\title{
Hot cracking mechanism affecting a non-weldable Ni-based superalloy produced by Selective Electron Beam Melting
}

\author{
Edouard Chauvet ${ }^{1}$, Paraskevas Kontis ${ }^{2}$, Eric A. Jägle ${ }^{2}$, Baptiste Gault ${ }^{2}$, Dierk Raabe ${ }^{2}$, Catherine \\ Tassin $^{1}$, Jean-Jacques Blandin ${ }^{1}$, Rémy Dendievel ${ }^{1}$, Benjamin Vayre ${ }^{3}$, Stéphane Abed ${ }^{3}$, Guilhem Martin ${ }^{1 \#}$ \\ 1. Univ. Grenoble Alpes, CNRS, Grenoble INP, SIMaP, F-38000 Grenoble, France \\ 2. Max-Planck-Institut für Eisenforschung GmbH, Max-Planck-Strasse 1, 40237 Düsseldorf, Germany \\ 3. Poly-Shape, 235 Rue des Canesteu -ZI La Gandonne 13300 Salon-de-Provence, France \\ \# Corresponding Author: \\ Email: guilhem.martin@simap.grenoble-inp.fr \\ Phone: $+33(0) 476826342$
}

\section{Abstract}

A non weldable nickel-based superalloy was fabricated by powder bed-based selective electron beam melting (S-EBM). The as-built samples exhibit a heterogeneous microstructure along the build direction. A gradient of columnar grain size as well as a significant gradient in the $\gamma^{\prime}$ precipitate size were found along the build direction. Microstructural defects such as gas porosity inherited from the powders, shrinkage pores and cracks inherited from the S-EBM process were identified. The origins of those defects are discussed with a particular emphasis on crack formation. Cracks were consistently found to propagate intergranular and the effect of crystallographic misorientation on the cracking behavior was investigated. A clear correlation was identified between cracks and high angle grain boundaries (HAGB). The cracks were classified as hot cracks based on the observation of the fracture surface of microtensile specimens machined from as-built S-EBM samples. The conditions required to trigger hot cracking, namely, presence of a liquid film during the last stage of solidification and thermal stresses are discussed within the framework of additive manufacturing. Understanding the cracking mechanism enables to provide guidelines to obtain crack-free specimens of non-weldable Ni-based superalloys produced by S-EBM.

Keywords: Electron beam Melting; Ni-based superalloys; Hot cracking; Grain boundaries; Liquid film; micro-segregations

\section{Introduction}

Precipitation strengthened Ni-based superalloys have been a one of the great breakthroughs in materials science enabling the development of advanced and fuel efficient aeroengines. Since the 1950s, this class of superalloys is in continuous development to achieve better creep and oxidation resistance, lower fatigue crack growth rate and high yield stress for service temperatures up to $1000^{\circ} \mathrm{C}$. These superalloys are typically strengthened by ordered, coherent intermetallic precipitates such as $\gamma^{\prime}-\mathrm{Ni}_{3}(\mathrm{Al}, \mathrm{Ti})$ or $\gamma^{\prime \prime}-\mathrm{Ni}_{3} \mathrm{Nb}$. Different processes can be used to produce parts made of this class of Ni-based superalloys: casting [1], 
directional solidification [2-7], and powder metallurgy [8-10]. With the recent development of new processing and advanced manufacturing routes, in particular additive manufacturing, there is an increasing demand for producing high-temperature components made of such Nibase superalloys. Key drivers for this include the ability to produce complex netshape components without the restrictions of traditional machining, thereby enabling optimized cooling channels that allow for higher service temperatures as well as the ability to rapidly produce small batches of complex parts without the prohibitive costs and lead times of traditional casting techniques.

Until recently, the community strongly focused on the well-known alloy Inconel 718, see e.g. [11-16], as it can be quite efficiently produced by additive manufacturing without producing critical defects. Wide processing windows have been identified for the two powder bed-based techniques selective laser melting process (SLM) $[13,16]$ and S-EBM $[12,17]$. This is not surprising as Inconel 718 is usually considered to be a weldable superalloy due to its low content of $\gamma^{\prime}$ forming elements (Al and Ti) [18], instead relying on $\gamma^{\prime \prime}-\mathrm{Ni}_{3} \mathrm{Nb}$ as strengthening precipitate phase. However, to achieve higher creep resistance under high load, superalloys with between 40 and $80 \%$ volume fraction of $\gamma^{\prime}$ are required. Such superalloys include Inconel 738 [19, 20], CMSX-4 [21, 22], René 142 [23] or CM247LC [24], which have hence recently attracted attention for usage in additive manufacturing processes. Those alloys contain comparatively high contents of $\mathrm{Al}$ and $\mathrm{Ti}$, are classified as non-weldable, and, as a result, are prone to cracking and hence turn out to be very challenging to produce defect free by additive manufacturing [20, 24-27].

Different mechanisms have been suggested in the welding literature to explain the observed cracking tendency [18]: solidification cracking [2] and liquation cracking [28] that require the presence of liquid, or strain-age cracking [18] and ductility-dip cracking [18] that occur at the solid state. 
The objective of the present work is to elucidate the mechanism and the origin of cracking in a non-weldable Ni-based superalloy fabricated by S-EBM. Using detailed microstructural characterization, combining techniques such as electron microscopy, electron backscattered diffraction and atom probe tomography, we identify a number of common features that provide insights into the origin of the cracks and discuss those in light of the models generally accepted for hot cracking in conventional processing routes.

\section{Experimental procedures}

\subsection{Powder characteristics}

The prealloyed powders were produced using vacuum induction melting (VIM) gasatomization with Ar and provided by ERASTEEL (Spain). The material under investigation is a non weldable Ni-Co-Cr-Mo-Al-Ti-B nickel-based superalloy containing significant amounts of $\mathrm{Cr}, \mathrm{Co}$ and $\mathrm{Mo}$ and with $\mathrm{Ti}+\mathrm{Al}$ wt.\% = 8.6. The exact chemical composition of the atomized powder cannot be indicated for industrial confidentiality reasons. The asreceived powder morphology and microstructure were characterized using a Zeiss Ultra field emission gun scanning electron microscope (FEG-SEM). The as-received powders mostly exhibit a spherical morphology with a few irregular particles and a relatively high density of satellites, see Figure 1a. Every powder particle is polycrystalline as revealed by the inverse pole figure electron backscattered diffraction map (IPF-EBSD) shown in Figure 1b. Some of the particles contain spherical pores corresponding to entrapped gas during the atomization process (Figure 1c). The powder size distribution was determined by laser granulometry (MALVERN Mastersize 3000), giving an average powder particle size of approximately $\sim 75$ $\mu \mathrm{m}$. The flowability and relative powder density were measured based respectively on the Metal Powders Industry Federation standards 3 and 4. The powder bed relative density was measured to be $53.6 \%$ and a flow time of $16.0 \pm 0.1$ seconds was found for $50 \mathrm{~g}$ of powders going through a $2.54 \mathrm{~mm}$ diameter orifice (Hall flowmeter). 


\subsection{Sample manufacturing}

The as-received prealloyed powders were loaded into an ARCAM A1 Electron Beam Melting (S-EBM) machine operating at $60 \mathrm{kV}$ accelerating voltage under a controlled pressure of He set to $2.10^{-3}$ mbar. The powder was deposited by layers of $50 \mu \mathrm{m}$ on a stainless steel plate (XY-plane), then slightly consolidated with a widely defocused beam and finally selectively melted using the automatic mode according to the input CAD geometry. The powder bed was slightly consolidated during the preheating stage in order to improve the mechanical behavior and electrical conductivity. This preheating stage turns out to be the key parameter to achieve a stable process: a smoke-free ${ }^{1}$ processing windows as well as a degree of consolidation that further enables easy removal of the powder at the end of the fabrication. A suitable temperature for preheating is therefore a temperature that roughly corresponds to the first stage of sintering, i.e. formation of necks between particles without densification. Here, the preheating temperature was selected so as to have an operating temperature of approximately $1050^{\circ} \mathrm{C}$. Specimens with dimensions $23 \times 23 \times 30 \mathrm{~mm}$ (see Figure 2a) were produced following a standard melting strategy, in which the beam scans the area defined by the CAD file in a snake-like way (meander) with a line offset of $0.1 \mathrm{~mm}$. The temperature profile measured below the start plate is displayed in Figure $\mathbf{2 b}$ where the different processing stages are also indicated.

In the S-EBM, the processing parameters vary spatially according to the geometry of the part (here cubes) when using the automatic mode. This is a typical characteristic of the SEBM process in comparison to other AM technologies. Here, every layer was melted with the exact same melting parameters: there was no change between layer $n^{\text {th }}$ and layer $n+1^{\text {th }}$ except for a $90^{\circ}$ rotation of the scanning direction. Please note that we only focused on the center of the cube samples, i.e. in the regions unaffected by the contours.

\footnotetext{
${ }^{1}$ Smoke is defined as the phenomenon occurring when electrostatic repulsive forces between negatively charged powder particles becomes significant leading to powder particle splashing.
} 


\subsection{Microstructural Characterization}

The S-EBM-samples were polished down to $0.04 \mu \mathrm{m}$ colloidal silica finish and were observed by optical microscopy along the vertical cross sections which corresponds to the XZ-plane, i.e. along the build direction $(B D=Z)$. Electron Backscattered Diffraction (EBSD), Energy Dispersive X-ray Spectroscopy (EDX) and SEM imaging were performed in a ZEISS Ultra FEG-SEM and data were collected using the OIM-TSL software. EBSD maps were collected using an acceleration voltage of $20 \mathrm{kV}$ on polished samples so as to analyze the microstructure and microtexture of the as-built specimens. $1 \mathrm{~mm}^{2}$-EBSD maps were acquired in the region affected by cracks (upper part of the samples). Ten EBSD maps of $1 \mathrm{~mm}^{2}$ were analyzed so as to ensure the statistical reliability of the results. EDX analyses were performed using an acceleration voltage of $15 \mathrm{kV}$ and an aperture of $90 \mu \mathrm{m}$ on flat polished samples in order to investigate qualitatively element segregations in the as-built samples. In addition, the microstructure was revealed using a fresh glyceregia etchant $\left(15 \mathrm{~mL} \mathrm{HCl}+5 \mathrm{~mL} \mathrm{HNO}_{3}+10\right.$ $\mathrm{mL}$ Glycerol). The $\gamma / \gamma^{\prime}$ microstructure was observed using an Ultra Zeiss FEG-SEM in secondary electron mode (SE) for etched samples and backscattered electron (BSE) contrast for polished samples. The size of the precipitates was estimated by image analysis based on SE-SEM micrographs acquired on etched specimens. At each position, at least 5 images were used to have an estimation of the precipitate size.

To investigate small scale segregations, site specific lift-outs were prepared for atom probe tomography (APT) using an FEI Dual Beam FIB Helios 600. Specimens were extracted from regions at the tip of cracks, following the procedures described in [29]. Samples were analyzed using a Cameca LEAP3000X HR instrument operating in laser mode with pulse rate at $200 \mathrm{kHz}$, pulse energy $0.4 \mathrm{~nJ}$ and temperature $50 \mathrm{~K}$. Data reconstruction and analyses were performed in the commercial package IVAS 3.6.14. and compositions were extracted from composition profiles in the form of proximity histograms, see [30]. 


\subsection{Mechanical Characterization}

Microhardness measurements were performed using a Wilson Tukon 1102 Vickers Tester. A $1 \mathrm{~kg}$ load was used and 20 measurements were carried out at each position along the Z-direction $(=\mathrm{BD})$. The error was estimated by computing the standard deviation over the 20 measurements made at each position.

To identify the reasons for cracks formation, tensile micro-specimens (gauge length $=$ $6 \mathrm{~mm}$, width $=2 \mathrm{~mm}$, thickness $=1 \mathrm{~mm}$ ) were machined from the as-built S-EBM cubic samples at different positions along the build direction with the tensile axis aligned along the $\mathrm{X}$ direction as shown in Figure 2c. Tensile tests were performed at room temperature using a 3300 Instron universal testing machine with an initial displacement rate of $5 \mathrm{~mm} / \mathrm{min}$. Note that the objective of the tensile tests was less to provide quantitative data regarding the mechanical properties of the fabricated materials but rather to break the samples under wellcontrolled and reproducible conditions and subsequently observe the fracture surface under secondary electron contrast. In total, ten micro specimens were deformed under tension up to fracture.

\section{Experimental Results}

\subsection{Microstructural gradients}

Careful observations of the $\mathrm{XZ}$ cross section along the entire sample height reveal typical features of parts manufactured by S-EBM. In particular, columnar grains that grow epitaxially along the build direction across several layers were found, which also corresponds to the main direction of the thermal gradient, as shown in Figure 3a. EBSD maps acquired at different positions along the Z-direction are displayed in Figure $\mathbf{3 b}$ and confirm these observations. Also, the EBSD maps reveal that the samples are strongly textured and exhibit a typical fiber texture of directionally solidified Ni-based superalloy, i.e. a preferential growth of the $<001>$ direction along $\mathrm{Z}$ and random orientation in the $\mathrm{XY}$ plane $[17,31,32]$. 
Significant microstructural heterogeneities were observed at different scales. At the grain scale, a gradient of columnar grain width along the build direction is readily visible in Figure 3b. The width of the columnar grain increases slightly from $\sim 30 \mu \mathrm{m}$ at $\mathrm{Z}=1 \mathrm{~mm}$ to $\sim 150$ $\mu \mathrm{m}$ at $\mathrm{Z}=10 \mathrm{~mm}$, as illustrated in Figure 4a. As the height of the sample further increases, the columnar grain width increases substantially to achieve very large columnar grains of approximately $1 \mathrm{~mm}$ width at $\mathrm{Z}=25 \mathrm{~mm}$. In contrast, the grain boundary density decreases from bottom to top as readily visible in Figure 4a. Within the grains themselves, a significant variation in the size of the $\gamma^{\prime}$ precipitates was observed as illustrated in Figure 3c and Figure 4b. Note that in Figure 3 the EBSD maps and BSE-SEM images are not necessarily shown at the same positions because the grain and precipitate size evolution do not occur at the same position along Z. The general observation was that the size of the $\gamma^{\prime}$ precipitates was increasing from the top to the bottom of the specimen. In particular, close to the top surface ( $\mathrm{Z}$ $=29 \mathrm{~mm}$ ) the size of the $\gamma^{\prime}$ precipitates is $100 \pm 20 \mathrm{~nm}$. The size of the $\gamma^{\prime}$ precipitates dramatically increased to approximately $500 \mathrm{~nm} \pm 100 \mathrm{~nm}$ at $\mathrm{Z}=25 \mathrm{~mm}$, to almost plateau at approximately $600 \mathrm{~nm} \pm 100 \mathrm{~nm}$ at $Z=5 \mathrm{~mm}$. This gradient of precipitate size is also consistent with the hardness profile performed along the build direction, see Figure $\mathbf{4 b}$. As expected, the maximum hardness $(490 \mathrm{HV}$ ) was found at $\mathrm{Z}=29 \mathrm{~mm}$ (i.e. $1 \mathrm{~mm}$ below the top surface) where the precipitates exhibit the smallest observed size whereas a rather constant hardness around $400 \mathrm{HV}$ was measured from $\mathrm{Z}=0$ to $27 \mathrm{~mm}$. The hardness map displayed in Figure 4c is also consistent with the previous reported results and show that the hardness is relatively uniform at each Z- position. Low hardness values are sometimes observed and has to be linked to the presence of defects such as cracks or pores.

\subsection{Defects: pores}

$\mathrm{XZ}$ as well as $\mathrm{XY}$ cross sections showed no "lack of fusion-type defects", which correspond to unmelted zones leading to incomplete bonding between successive layers [33]. 
The samples were almost fully dense ( $>99.5 \%$ measured by image analysis). However, other types of defects were identified such as pores and cracks, as illustrated in Figure 5.

Regarding the pores, two different types were identified based on their morphology and location in the sample. A first type corresponds to spherical pores randomly distributed with a diameter in the range of 20-50 $\mu \mathrm{m}$ (Figure 5a). Their morphology of near-perfect spheres agrees with the internal pores observed in the as-received powders (see Figure 1c). This suggests that those pores were partly inherited from the powder atomization process of the initial powder particles, and they will be referred to as gas porosity. This is a relatively classical observation, often reported for parts made by powder based additive manufacturing technologies, see e.g. [33]. The porosity within the as-received powder batch as well as in the as-built samples were quantified. The initial powder batch contained $0.5 \%$ porosity while the as-built samples exhibited only $0.4 \%$ porosity. This shows that some of the initial spherical pores have disappeared during melting ( $\Delta=-0.1 \%$ porosity). This can be accounted by the fact that in S-EBM, the melting occurs up to 2-3 layers down and even more depending on the processing conditions, therefore there is extensive time for some gas porosity to escape to the ambient low vacuum environment. However, one has to keep in mind that other type of porosity like the ones described below was observed, see Figure 5b. This shows that the gas porosity has likely been reduced even more significantly.

The second type consists of well-aligned chains of rounded-shape pores along the columnar grain growth direction with a typical diameter $<5 \mu \mathrm{m}$ (Figure 5b). We assume that their origin is a consequence of the intragranular dendrites secondary arms coalescence during the last stage of solidification $[3,6,34]$. The distance between two chains of pores can be defined as the interdendritic spacing (distance between dendrite trunks). Those pores hence form as bridging occurs between dendritic secondary arms: the liquid can no more reach the isolated 
channels to compensate for the volume contraction associated with the liquid-to-solid phase transformation (i.e. solidification). Those pores are referred to as microshrinkage.

\subsection{Defects: cracks and crack path propagation}

The most critical defects were undoubtedly cracks running along the build direction over several millimeters, as shown in Figure 5c. Interestingly, cracks were only observed in the range $\mathrm{Z}=12-30 \mathrm{~mm}$ when the columnar grain width was larger than approximately $150 \mu \mathrm{m}$. In the range $\mathrm{Z}=0-12 \mathrm{~mm}$, no cracks were detected. The EBSD analysis demonstrates that crack propagation always occurs along grain boundaries, as clearly shown in Figure 6a. The cracks can therefore be defined as intergranular. $\sim 100$ boundaries over the region of interest were analyzed and classified based on their misorientation angle and their cracking susceptibility, as reported in Figure 6b, which suggests that high angle grain boundaries (HAGB, misorientation $>15^{\circ}$ ) are sensitive to cracking whereas the low angle grain boundaries (LAGB, misorientation $<15^{\circ}$ ) remain uncracked. This result is consistent with the literature dealing with welding and casting of non-weldable nickel-base superalloys $[1,2,35]$.

\subsection{Presence of a liquid film}

The fracture surface of the S-EBM samples machined in the upper part $(20<\mathrm{Z}<30$ $\mathrm{mm}$ ) shows a dendritic morphology with a limited development of secondary arms, giving evidence of the presence of a liquid film [3], visible in Figure 7a. In other words, cracking most likely must have occurred when a liquid film was wetting the dendrites during the last stage of solidification. Samples machined at lower $Z$ positions $(5<Z<15 \mathrm{~mm})$, where no cracks were detected, exhibit a fracture surface with some regions showing dimples typical of a ductile failure and other smaller regions indicating the presence of liquid, see Figure $\mathbf{7 b}$. The different features highlighted on the fracture surface could be associated to two different types of defects described previously. Indeed, the fracture surface with a full dendritic morphology was associated to cracks that propagate along HAGB as shown in Figure 6. The 
fracture surface showing a ductile failure, with only few traces of dendritic morphology, had to be linked to regions where the coalescence of secondary arms was significant. These observations finally led us to exclude solid-state cracking mechanisms, such as strain-age cracking or ductility dip cracking, and point to a mechanism requiring the presence of liquid films. Therefore, the origin of the presence of a liquid film has to be clarified.

\subsection{Local enrichment at grain boundaries}

Characterizing the vicinity of grain boundaries is of major interest as compositional local enrichment to grain boundaries can be considered as a signature of the original Scheil type enrichment in the liquid during the very last stages of solidification.

Regions of interest near the tip of cracked HAGB in the upper part of the build $(Z=20 \mathrm{~mm})$ are marked in Figure 8a-b. Intergranular semi-continuous particles were observed in terms of a bright contrast in the backscattered image in Figure 8b. Similar particles can also be seen decorating some of the grain boundaries in the lower part of the build, at $Z=5 \mathrm{~mm}$ (Figure 8c). EDX mapping of the main alloying elements was performed at one of the cracks tips, significant partitioning of $\mathrm{Cr}$ and Mo was found within these particles, whereas other elements were not detected as illustrated in Figure 9.

In additively manufactured materials, the solidification velocity and the thermal gradient are relatively high $\left(\mathrm{V} \sim 10^{1}-10^{2}{ }^{\circ} \mathrm{C} \cdot \mathrm{mm}^{-1}\right.$ and $\left.\mathrm{G} \sim 10^{2}-10^{4}{ }^{\circ} \mathrm{C} \cdot \mathrm{s}^{-1}\right)$ compared to those measured in conventional casting $\left(\mathrm{V} \sim 10^{-1}-10^{-2}{ }^{\circ} \mathrm{C} \cdot \mathrm{mm}^{-1}\right.$ and $\left.\mathrm{G} \sim 1-10{ }^{\circ} \mathrm{C} . \mathrm{s}^{-1}\right)$. Thus, the degree of segregations is expected to be much lower in S-EBM samples than in conventionally cast ones, see e.g. [21, 22, 25].

However, the presence of particles containing significant amounts of $\mathrm{Cr}$ and $\mathrm{Mo}$ at the grain boundaries suggests a local compositional enrichment of these elements. Thus, in order to accurately measure the composition of these particles, site specific lift-outs were prepared for atom probe tomography (APT). Specimens were extracted from regions near the tip of cracks, 
typically regions such as the one depicted in Figure 8b. The second phase particles showing a Cr- and Mo-enrichment revealed by EDX were clearly identified by APT as intergranular borides. Three different types of intergranular borides were identified with stoichiometry ratios corresponding to $\mathrm{MB}, \mathrm{M}_{2} \mathrm{~B}$ and $\mathrm{M}_{5} \mathrm{~B}_{3}$, respectively, as summarized in Table $\mathbf{1}$. All three types of borides were observed to be Mo- and Cr-rich whereas other elements contribute in smaller quantities. An APT 3D reconstruction containing both $\mathrm{MB}$ and $\mathrm{M}_{2} \mathrm{~B}$ borides alongside an intergranular $\gamma^{\prime}$ particle is shown in Figure 10a-b. Note that the larger the columnar grain width (i.e. the lower the grain boundary density), the more the grain boundaries were decorated by borides, see comparison between Figure 8a and Figure 8b. In other words, it means that the boride density per grain boundary unit length is higher in presence of wide grains. Note that the borides preferentially sit at HAGB and that LAGB were found to be boride-free.

Proximity histograms, which are elemental composition profiles measured as a function of the distance from the $\gamma^{\prime} / \mathrm{M}_{2} \mathrm{~B}$ interface are presented in Figure 10c. The interface is defined as an iso-concentration surface encompassing the region of the data containing more that 34 at.\% Ni. The composition profiles across the $\gamma^{\prime} / \mathrm{M}_{2} \mathrm{~B}$ interface differ from the typical S-curve observed for such interfaces, see typically [29]. Three distinct regions can be seen in Figure 10c: a first region on the left corresponding to the boride, a second region highlighted in red, see the change of slope observed at a distance of about $2.5 \mathrm{~nm}$ in Figure 10c, and a third region (on the right) corresponding to the $\gamma^{\prime}$ precipitate. This $2-4 \mathrm{~nm}$ wide film at the interface between the boride and the $\gamma^{\prime}$ precipitate was not previously observed or reported in samples cast by traditional routes. Its composition does not correspond to any of the typical expected phases in this alloy. It is likely that this thin film corresponds to the residual liquid present in the last stage of solidification. Our measurements indicate that this 
region is highly enriched in B with a concentration measured in this case $\sim 2-3 \%$ at. $\%$, i.e. a quantity substantially higher than the B content in the bulk chemistry $(0.083$ at.\%).

\begin{tabular}{ccccc}
\hline & B & Cr & Mo & Other elements \\
\hline $\mathbf{M B}$ & 52.2 & 25.1 & 14.6 & Bal. \\
\hline $\mathbf{M}_{\mathbf{2}} \mathbf{B}$ & 33.3 & 20.1 & 35.5 & Bal. \\
\hline $\mathbf{M}_{\mathbf{5}} \mathbf{B}_{\mathbf{3}}$ & 36.6 & 20.3 & 36.8 & Bal. \\
\hline
\end{tabular}

Table 1. Chemical composition of borides as measured by atom probe tomography (at.\%).

\subsection{Presence of thermal stresses}

The presence of an intergranular liquid film itself is not sufficient to result in cracking. Indeed, solidification shrinkage or thermal stresses should be involved to trigger the hot cracking mechanism.

Cracks are an indirect observation of the presence of thermal stresses pulling on the liquid film during the last-stage of solidification. The development of significant thermal stresses during the solidification and subsequent cooling can lead to residual stresses in the final parts. An original method was employed to demonstrate the presence of significant residual stresses inherited from the S-EBM process. As-built S-EBM samples were annealed to $1190^{\circ} \mathrm{C} / 4 \mathrm{~h}$ and subsequently air quenched. Such an annealing corresponds to the typical solutionizing heat treatment of the alloy investigated. Recrystallized grains can be observed, see in regions marked by black arrows in Figure 11. Note that before annealing, all the grains exhibited a columnar morphology. The observation of recrystallized grains suggests the presence of plastic strain during the additive manufacturing operations, leading to a high density of dislocations, the driving force for recrystallization. The latter observation indicates clearly that substantial strain energy was stored in the microstructure of the as-built S-EBM samples. This supports the idea that significant residual stresses are likely present in the asbuilt parts. Note that even though thermal stresses are thought to play a crucial role in the hot cracking mechanism, it should be highlighted that the level of residual stresses is expected to 
be significantly lower in S-EBM parts than in SLM parts because of the preheating stage that helps to limit temperature gradients during local melting [36].

\section{Discussion}

\subsection{Origin of the microstructural gradients}

The gradient in the width of the columnar grain can be seen analogous to single crystal growth by the Bridgman method. The Bridgman technique is based on directional solidification by moving a melt from the hot zone to the cold zone of the furnace [37]. In the S-EBM samples, the situation is very similar as the hot zone corresponds to the layers under construction (top layers), the underlying layers, typically thermally unaffected by the addition of new layers, act as the cold zone. Over the first millimeter, the microstructure consists of relatively small randomly textured columnar grains resulting from melting of the powder particles. Then columnar grains oriented along the $<001>$ direction grow selectively by epitaxy across several layers along the build direction corresponding to the main direction of the thermal gradient. The re-melting of several layers promotes this epitaxial growth. At 20 $\mathrm{mm}$, the microstructure is strongly textured with a $<001>$-fiber texture and consists of relatively wide columnar grains $(\sim 1 \mathrm{~mm})$. Finally, when the subsequent deposited layers are melted, up to 3-4 layers underneath are also re-melted and therefore the wide columnar grains oriented along the 001 direction act as seed for the next layers. In other words, it means that by selecting appropriate melting strategies, it should be possible to grow single crystal samples within the S-EBM machine.

The gradient in the $\gamma^{\prime}$ size can be explained by the high temperature process (preheating $\sim 1050^{\circ} \mathrm{C}$ ). Depending on the Z-position probed, the different layers were annealed for different times and consequently significant growth and coarsening occurred at the bottom of the sample. Just below the top surface, fine precipitates were observed because this region was not re-melted neither re-heated (last layer). The fine precipitates observed in 
the top region might have formed at low temperature during the cooling stage [38]. The cooling rate in this particular region was insufficiently slow to achieve significant coarsening of the precipitates.

\subsection{Cracking mechanism}

\subsubsection{Solidification cracking vs. liquation cracking}

The observation of the fracture surface of the tensile specimens shows that cracks develop in presence of liquid. Both mechanisms, namely solidification cracking and liquation cracking, require the presence of liquid films. Therefore, it allows us to exclude any mechanism occurring at the solid-state. That being said, discriminating liquation cracking from solidification cracking is not straightforward as it could be in directional solidification experiments, especially in our case because the thermal path can turn out to be very complex: melting, re-melting, partial-re-melting, cyclic annealing etc. Again welding literature of Nibased superalloys can help us to tend towards one mechanism rather than another.

Ojo et al. [39] have reported the formation of secondary solidification constituents formed from the interdendritic liquid such as $\mathrm{MC}$-type carbides, $\mathrm{M}_{3} \mathrm{~B}_{2}$-boride and $\mathrm{Ni}_{7} \mathrm{Zr}_{2}$ in a fusion zone of a Tungsten Inert Gas welded Inconel 738LC superalloy. The liquation of those secondary solidification constituents was suspected to be at the origin of the microfissuring observed in the HAZ. Note that carbides were never observed in the material investigated here. Unlike in Ojo et al. in [39], a close examination of the cracked boundaries using high magnifications SEM images did not reveal the presence liquated borides. In addition, no obvious traces of $\gamma^{\prime}$ constitutional liquation as reported by Zhong et al. in [40] or Ojo et al in [41] was detected. Finally, the fracture surface exhibits a fully dendritic morphology. This tips the scales in favor of solidification cracking. We also suspect that the B-local enrichment intensifies when the liquid film is melted several times which is the case in the S-EBM 
process. Further investigations would be required to solve undoubtedly the cracking mechanism.

\subsubsection{Liquid film}

\subsubsection{Grain boundary compositional enrichment}

EDX and APT results as well as literature data [8, 29, 42, 43] show the presence of borides along the grain boundaries. Three types of borides were identified, namely, $\mathrm{MB}, \mathrm{M}_{2} \mathrm{~B}$ and $\mathrm{M}_{5} \mathrm{~B}_{3}$. Similar types of borides were already reported before to occur in nickel-based superalloys, see e.g. [8, 29, 42, 43]. Lemarchand et al. [8] have investigated the grain boundary structure-segregation relationship by TEM and APT in a similar alloy elaborated by powder metallurgy including the hot isostatic pressing route (HIP) and the presence of borides was also reported.

These borides were also essentially composed of $\mathrm{Cr}$ and Mo and identified as $\mathrm{M}_{2} \mathrm{~B}$ similarly to some of the borides analyzed in the present work. Interestingly, the size of the borides observed in [42] was about two orders of magnitude smaller $(15 \mathrm{~nm})$ than those observed in the present study $(\sim 1 \mu \mathrm{m})$. The presence of such Mo and $\mathrm{Cr}$ containing borides support the idea of local enrichments of these solutes to grain boundaries. Lemarchand et al. [8] emphasized such local enrichment in Cr, B and Mo along the grain boundary in the form of a continuous film wetting the grain boundaries and similar local compositional enrichment was also reported in an Astroloy [44-46]. Local B enrichment in the regions that are going to become the grain boundaries upon impingement is expected to contribute to solidification cracking [19]. Indeed, even in very small amount, some elements can have a deleterious effect on the solidification cracking susceptibility of Ni-based superalloys. The literature dealing with welding and weldability of Ni-based superalloys turns out to be relevant towards the effect of minor elements such as B on the hot cracking susceptibility, see e.g. [4, 6, 19, 47]. This detrimental influence was attributed to (i) its strong segregation tendency to grain 
boundaries [8, 29, 42, 48, 49] and (ii) its ability to lower the solid/liquid interface energy [18] promoting cracking by extensive wetting of the solid dendrites by the liquid film still present during the very last stage of solidification. As it was shown in section 3.1., the grain boundary density (HAGB) decreases along the $\mathrm{Z}$ direction (Build Direction), resulting in shorter grain boundary lengths per unit area. This means that the degree of compositional segregation might be reduced in presence of small grains due to the resulting higher grain boundary density and lower specific Scheil type segregation content. Conversely, in presence of wide columnar grains (i.e. low grain boundary density), the degree of segregation during the solidification is expected to increase, resulting in a higher concentration of $\mathrm{B}$ and consequently to an increased volume fraction of borides, as confirmed by the comparison between Figure 8a and $\mathbf{b}$. This leads us to suspect that if one aims at decreasing the hot cracking susceptibility, the boron content should be reduced to limit the formation of low melting liquid film.

\subsubsection{Possible effect of micro-segregations on the liquid film}

To evaluate roughly the possible effect of micro-segregations on the solidification of the investigated material, thermodynamic calculations using the ThermoCalc Software AB [50] relying on the data base dedicated to Ni-based superalloys (TCNI8) were performed based respectively, on the equilibrium and non-equilibrium (Scheil-Gulliver: no diffusion in the solid state and infinite diffusion in the liquid) assumptions. The calculations were run by retaining only the phases that were observed in the microstructures of the S-EBM samples, namely: $\gamma, \gamma^{\prime}, \mathrm{MB}, \mathrm{M}_{2} \mathrm{~B}, \mathrm{Cr}_{5} \mathrm{~B}_{3}$ (for the $\mathrm{M}_{5} \mathrm{~B}_{3}$ borides) and the liquid phase. Even if the situation is supposed to be more complicated in the S-EBM samples because of the very complex thermal path (re-melting, re-heating...), it is rather clear that in presence of micro- 
segregations (Scheil-Gulliver), the solidus point is significantly lower, leading to a larger solidification range: $\sim 600^{\circ} \mathrm{C}$ whereas it was estimated to be $\sim 200^{\circ} \mathrm{C}$ under equilibrium conditions, see Figure 12. Due to the inability to simulate back-diffusion in the solid, the Scheil model gives a good estimation of the liquidus temperature but overestimates solute segregation and thus predicts very low solidus temperature.

This result means that when micro-segregations are considered, liquid films will prevail and hence still be present also at lower bulk temperatures. The argument of the solidification range, i.e. strictly speaking the difference between the solidus and liquidus temperatures, has to be considered carefully regarding the solidification cracking susceptibility. Actually, some references doubt that the segregation-dependent solidification range is a critical factor for cracking, see e.g. $[3,51]$. It is rather suggested in these papers [51] that the factor that matter more is the difference in temperature when the fraction of solid $f_{s}$ changes from $\sim 0.95$ (coalescence fraction) to 1. In the literature, it is usually called the "critical temperature range" [3]: $\Delta T_{C T R}=\mathrm{T}\left(f_{S}=1\right)-\mathrm{T}\left(f_{S}=0.95\right)$. For our current alloy $\Delta T_{C T R}$ was estimated to be $\sim 100^{\circ} \mathrm{C}$ assuming thermodynamic equilibrium and $\sim 350^{\circ} \mathrm{C}$ assuming Scheil-Gulliver conditions. It is also interesting to note that the variation of the fraction of solid with temperature, $d f_{S} / d T$, within this critical temperature range $\Delta T_{C T R}$ is usually used in the definition of hot tearing criteria, see e.g. $[3,51] . d f_{S} / d T$ appears to be crucial for the hot tearing resistance because it determines the strain and strain rate during solidification.

For the Scheil assumption, the evolution of the liquid composition has been calculated so as to assess the liquid B-enrichment in the last stages of solidification. Interestingly, the liquid phase was found to be significantly enriched in boron in the temperature critical range $\left(f_{s}\right.$ 0.95-1), see Table 2. This supports the tendency to form low melting B-rich liquid films in the critical temperature range.

\begin{tabular}{lllllll}
\hline Temperature $\left({ }^{\circ} \mathbf{C}\right)$ & 1340 & 1200 & 1100 & 1050 & 1000 & 800 \\
\hline
\end{tabular}




\begin{tabular}{lllllll}
\hline $\boldsymbol{f}_{\boldsymbol{s}}$ & 0.06 & 0.87 & 0.94 & 0.96 & 0.97 & 0.99 \\
\hline B \%at. in the liquid & 0.08 & 0.56 & 1.31 & 1.76 & 1.99 & 1.09 \\
\hline
\end{tabular}

Table 2. Boron content in the liquid phase calculated at different temperatures using ThermoCalc based on the ScheilGulliver assumption.

\subsubsection{Last-stage solidification: theoretical model of Rappaz et al.}

Another important point that needs to be highlighted when discussing the mechanism leading to solidification cracking is the different coalescence behavior of dendrites belonging to the same grain (intragranular coalescence) and of dendrites located on both sides of a grain boundary (intergranular coalescence). The theoretical model on the very last stage of solidification developed by Rappaz et al. $[2,34]$ is particularly relevant to the discussion of the present results. In [34], Rappaz relied on the concept of "attractive" and "repulsive" boundaries depending on the crystallographic misorientation. An attractive boundary is defined in this work as a grain boundary where the coalescence among dendrite secondary arms occurs during the last stage of solidification contrary to a repulsive one for which a liquid film remains stable at lower temperatures delaying the occurrence of dendrite secondary arms coalescence. To discriminate attractive from repulsive boundary, Rappaz et al. $[2,34]$, compare the grain boundary energy, $\gamma_{g b}$ to twice the solid-liquid interface energy $\gamma_{s l}$. When $\gamma_{g b}<2 \gamma_{s l}$, the liquid film is unstable and bridging occurs between dendrite secondary arms: "attractive boundary" (corresponds typically to dendrites belonging to the same grain). When $\gamma_{g b}>2 \gamma_{s l}$, the liquid film remains stable to a lower temperature ("repulsive" boundary) corresponding to the critical coalescence undercooling, denoted $\Delta T_{c c}$ and defined for a pure metal as: $\Delta T_{c c}=\left(\gamma_{g b}-2 \gamma_{s l}\right) / \Delta S_{f} \delta$, where $\Delta S_{f}$ is the entropy of fusion per unit volume and $\delta$ the thickness of the diffuse interface $(\sim 1 \mathrm{~nm})$. In other words, it means that the dendrites arms within the same grain start to coalesce at a higher temperature than the dendrites arms located on both sides of a grain boundary.

This model provides a physical background to explain why cracks develop preferentially at HAGBs and that LAGBs are not affected by solidification cracks. For 
HAGBs, the situation is rather clear. Indeed, the grain boundary energy is likely to exhibit high values (except for CSL- $\Sigma$ specific boundaries), therefore $\gamma_{g b}-2 \gamma_{s l}$ is expected to be $>0$. As a result, $\Delta T_{c c}$ is significant and consequently the liquid film remains stable at lower temperatures, see Figure 13a.

For LAGB (misorientation $<15^{\circ}$ ), the grain boundary energy drops suddenly when the misorientation decreases. Thus $\gamma_{g b}-2 \gamma_{s l}$ becomes smaller and smaller as the misorientation decreases. In this situation, $\Delta T_{c c}$ is negligible until it is reduced to 0 for a critical value of $\gamma_{g b}$ corresponding to the following case: $\gamma_{g b}-2 \gamma_{s l}=0$ (Figure 13b). The liquid film becomes unstable and bridging occurs. In these regions, strains could be transmitted by the bridges existing between the dendrite secondary arms avoiding the formation of cracks. In other words it means that depending on the misorientation, the behaviour of grain boundaries changes [52]. Based on Rappaz' model [34], it turns out that HAGBs remain wetted by the liquid film at lower temperature compared to LAGB, see Figure 13.

\subsubsection{Stresses/strain required to trigger hot cracking}

As mentioned previously, solidification cracking occurs when two conditions are combined: (i) presence of a liquid film and (ii) presence of sufficient thermal stresses. The first condition was largely discussed in section 4.2.1, the second one is discussed below.

At a macroscopic scale, the thermal stresses were associated with the solidification of the successive layers. The top layer is under tensile stress, because its shrinkage is limited by the already solidified layers. These tensile stresses in the top layers are thought to be very detrimental regarding the hot cracking issue as it would contribute to pull on the liquid film wetting the dendrites during the last stage of solidification. When the temperature reaches the 
coalescence temperature, bridging occurs between the dendrite secondary arms preventing liquid feeding and leading to the formation of solidification pores [3].

Some thermal stresses may also develop at the scale of the melt pool. Welding literature is again helpful to understand how thermal stresses developed and eventually lead to tensile stresses finally resulting in hot cracking. The work done by Feng et al. [53] and Babu et al. [54] show that the local stress fields that develop in the vicinity of the weld pool have a strong spatial dependency (position of the weld pool within in the specimen). They showed that a transverse tensile stress will lead to longitudinal weld centerline cracking whereas a longitudinal tensile stress will lead to transverse weld cracking. However, it is difficult to rationalize the nature of the cracks in our case: transverse or longitudinal centerline cracking based on those results. Indeed, the situation is much more complex in the S-EBM samples: Feng et al. [53] have investigated the stress fields around the weld pool during a single track. Here multiple weld tracks are required to melt a layer with a given degree of overlapping between the tracks and a raster-melt scan strategy is used. The stress fields are suspected to be significantly affected by the melting strategy used. For example, some authors have adapted the melting strategy in the S-EBM process to limit the development of thermal stresses and consequently of hot cracks, see e.g. [22].

As shown in the experimental results, no cracks were detected over the first few millimeters. It was reported in [55] that the stresses can increase along the build direction and can likely contribute to generate cracking when the stresses are high enough [55]. Therefore, it was thought that any cracking phenomenon occurs until a critical $\mathrm{Z}$ position, i.e. a critical level of thermal stresses is achieved. Another possible explanation is the effect of grain size or grain boundary density. Indeed, the crack free region corresponds to the lower part of the samples where the density of grain boundaries (HAGB) was the highest, see Figure 4a. Those results are consistent with the fact that the hot tearing resistance increases when the grain 
boundary fraction increases, see $[1,5,6]$. The beneficial effect of having small grains towards the hot tearing resistance is attributed to the fact that the strain is accommodated by more interfaces, i.e. HAGB.

\section{Summary and Conclusions}

The main conclusions emerging from the present work are:

- Samples of a non weldable Ni-based superalloy have been produced successfully by S-EBM without lack of fusion type defects.

- The S-EBM-samples exhibit a heterogeneous microstructure at the grain scale: gradient of columnar grain size along the building direction as well as within the grain: gradient of $\gamma^{\prime}$-precipitate size along the building direction.

- Various types of defects such as gas porosity, shrinkage pores and intergranular cracks have been identified. The origin of each category of defect was determined with a specific emphasis put on the origin of the cracks.

- The mechanism at the origin of crack formation in parts made of a nonweldable Ni-based superalloy made by S-EBM requires the presence of liquid films.

- The hot cracking susceptibility has been found to depend on the nature of the grain boundary misorientation, only HAGBs were affected by cracking.

- The presence of micron sized borides with stoichiometries corresponding to $\mathrm{MB}, \mathrm{M}_{2} \mathrm{~B}$ and $\mathrm{M}_{5} \mathrm{~B}_{3}$ as confirmed by APT suggests a significant local enrichment in $\mathrm{B}$ in the vicinity of the grain boundaries.

- Local compositional enrichment by minor elements, in particular $\mathrm{B}$, are thought to play a significant role to maintain a liquid film at lower temperature in comparison with the theoretically assumed equilibrium solidus temperature.

- The grain boundary energy which varies significantly between LAGB and HAGB has been also pointed out as a factor that can affect the stability of the liquid film. 
These results lead us to suggest a guideline to limit hot cracking in a non-weldable superalloy produced by S-EBM. It can be first suggested to reduce the boron content for limiting the formation of B-rich liquid films. Adjusting the process parameters to achieve solidification routes leading to fine grained microstructures $(\sim 100 \mu \mathrm{m})$ more resistant to hot cracking can also be considered to limit the development of hot cracks. The strain generated during the S-EBM process could be accommodated by a high density of interfaces while compositional segregation leading to the prevalence of a liquid film during the last stage of solidification would be reduced. Optimization of the processing parameters to produce crackfree samples with fine columnar grains, equiaxed grains or a single crystal is the topic of ongoing research in that context.

\section{Acknowledgements}

This work was performed within the framework of the Center of Excellence of Multifunctional Architectured Materials "CEMAM" n'AN-10-LABX-44-01 funded by the "Investments for the Future Program'. Dr Michel Suery and Dr. Frederic De Geuser are gratefully acknowledged respectively, for fruitful discussions and his help to build a collaboration between both groups. P. K., E. A. J., D. R. and B. G. are grateful to U. Tezins and A. Sturm for their technical support of the focus ion beam and atom probe tomography facilities at the Max-Planck-Institut für Eisenforschung.

\section{References}

[1] J. Zhang, R.F. Singer, Effect of grain-boundary characteristics on castability of nickel-base superalloys, Metallurgical and Materials Transactions A-Physical Metallurgy and Materials Science 35A(3) (2004) 939-946.

[2] N. Wang, S. Mokadem, M. Rappaz, W. Kurz, Solidification cracking of superalloy single- and bicrystals, Acta Materialia 52(11) (2004) 3173-3182.

[3] J. Zhang, R.F. Singer, Hot tearing of nickel-based superalloys during directional solidification, Acta Materialia 50(7) (2002) 1869-1879.

[4] J. Grodzki, N. Hartmann, R. Rettig, E. Affeldt, R.F. Singer, Effect of B, Zr, and C on Hot Tearing of a Directionally Solidified Nickel-Based Superalloy, Metallurgical and Materials Transactions APhysical Metallurgy and Materials Science 47A(6) (2016) 2914-2926.

[5] Y.Z. Zhou, A. Volek, R.F. Singer, Effect of grain boundary characteristics on hot tearing in directional solidification of superalloys, Journal of Materials Research 21(9) (2006) 2361-2370.

[6] Y.Z. Zhou, A. Volek, Effect of grain boundary fraction on castability of a directionally solidified nickel alloy, Scripta Materialia 54(12) (2006) 2169-2174.

[7] Y.Z. Zhou, A. Volek, Effect of dendrite arm spacing on castability of a directionally solidified nickel alloy, Scripta Materialia 56(6) (2007) 537-540.

[8] D. Lemarchand, E. Cadel, S. Chambreland, D. Blavette, Investigation of grain-boundary structuresegregation relationship in an N18 nickel-based superalloy, Philosophical Magazine A-Physics of Condensed Matter Structure Defects and Mechanical Properties 82(9) (2002) 1651-1669.

[9] G.A. He, F. Liu, L. Huang, Z.W. Huang, L. Jiang, Microstructure evolutions and nucleation mechanisms of dynamic recrystallization of a powder metallurgy Ni-based superalloy during hot 
compression, Materials Science and Engineering a-Structural Materials Properties Microstructure and Processing 677 (2016) 496-504.

[10] J. Jiang, J. Yang, T. Zhang, J. Zou, Y. Wang, F.P.E. Dunne, T.B. Britton, Microstructurally sensitive crack nucleation around inclusions in powder metallurgy nickel-based superalloys, Acta Materialia 117 (2016) 333-344.

[11] K.N. Amato, S.M. Gaytan, L.E. Murr, E. Martinez, P.W. Shindo, J. Hernandez, S. Collins, F. Medina, Microstructures and mechanical behavior of Inconel 718 fabricated by selective laser melting, Acta Materialia 60(5) (2012) 2229-2239.

[12] H.E. Helmer, C. Koerner, R.F. Singer, Additive manufacturing of nickel-based superalloy Inconel 718 by selective electron beam melting: Processing window and microstructure, Journal of Materials Research 29(17) (2014) 1987-1996.

[13] Q.B. Jia, D.D. Gu, Selective laser melting additive manufacturing of Inconel 718 superalloy parts: Densification, microstructure and properties, Journal of Alloys and Compounds 585 (2014) 713-721.

[14] A. Strondl, M. Palm, J. Gnauk, G. Frommeyer, Microstructure and mechanical properties of nickel based superalloy IN718 produced by rapid prototyping with electron beam melting (EBM), Materials Science and Technology 27(5) (2011) 876-883.

[15] J. Strossner, M. Terock, U. Glatzel, Mechanical and Microstructural Investigation of NickelBased Superalloy IN718 Manufactured by Selective Laser Melting (SLM), Advanced Engineering Materials 17(8) (2015) 1099-1105.

[16] Z.M. Wang, K. Guan, M. Gao, X.Y. Li, X.F. Chen, X.Y. Zeng, The microstructure and mechanical properties of deposited-IN718 by selective laser melting, Journal of Alloys and Compounds 513 (2012) 518-523.

[17] R.R. Dehoff, M.M. Kirka, F.A. List, K.A. Unocic, W.J. Sames, Crystallographic texture engineering through novel melt strategies via electron beam melting: Inconel 718, Materials Science and Technology 31(8) (2015) 939-944.

[18] J.C. Lippold, S.D. Kiser, J.N. DuPont, Welding Metallurgy and Weldability of Nickel-Base Alloys, WILEY ed., WILEY2009.

[19] M. Cloots, P.J. Uggowitzer, K. Wegener, Investigations on the microstructure and crack formation of IN738LC samples processed by selective laser melting using Gaussian and doughnut profiles, Materials \& Design 89 (2016) 770-784.

[20] R. Engeli, T. Etter, S. Hovel, K. Wegener, Processability of different IN738LC powder batches by selective laser melting, Journal of Materials Processing Technology 229 (2016) 484-491.

[21] M. Ramsperger, L.M. Roncery, I. Lopez-Galilea, R.F. Singer, W. Theisen, C. Koerner, Solution Heat Treatment of the Single Crystal Nickel-Base Superalloy CMSX-4 Fabricated by Selective Electron Beam Melting, Advanced Engineering Materials 17(10) (2015) 1486-1493.

[22] M. Ramsperger, R.F. Singer, C. Korner, Microstructure of the Nickel-Base Superalloy CMSX-4 Fabricated by Selective Electron Beam Melting, Metallurgical and Materials Transactions A-Physical Metallurgy and Materials Science 47A(3) (2016) 1469-1480.

[23] L.E. Murr, E. Martinez, X.M. Pan, S.M. Gaytan, J.A. Castro, C.A. Terrazas, F. Medina, R.B. Wicker, D.H. Abbott, Microstructures of Rene 142 nickel-based superalloy fabricated by electron beam melting, Acta Materialia 61(11) (2013) 4289-4296.

[24] L.N. Carter, C. Martin, P.J. Withers, M.M. Attallah, The influence of the laser scan strategy on grain structure and cracking behaviour in SLM powder-bed fabricated nickel superalloy, Journal of Alloys and Compounds 615 (2014) 338-347.

[25] B. Ruttert, M. Ramsperger, L.M. Roncery, I. Lopez-Galilea, C. Korner, W. Theisen, Impact of hot isostatic pressing on microstructures of CMSX-4 Ni-base superalloy fabricated by selective electron beam melting, Materials \& Design 110 (2016) 720-727.

[26] M.M. Attallah, R. Jennings, X.Q. Wang, L.N. Carter, Additive manufacturing of Ni-based superalloys: The outstanding issues, MRS Bulletin 41(10) (2016) 758-764.

[27] L.N. Carter, X. Wang, N. Read, R. Khan, M. Aristizabal, K. Essa, M.M. Attallah, Process optimisation of selective laser melting using energy density model for nickel based superalloys, Materials Science and Technology 32(7) (2016) 657-661.

[28] Y. Chen, F.G. Lu, K. Zhang, P.L. Nie, S.R.E. Hosseini, K. Feng, Z.G. Li, Dendritic microstructure and hot cracking of laser additive manufactured Inconel 718 under improved base cooling, Journal of Alloys and Compounds 670 (2016) 312-321. 
[29] P. Kontis, H.A.M. Yusof, S. Pedrazzini, M. Danaie, K.L. Moore, P.A.J. Bagot, M.P. Moody, C.R.M. Grovenor, R.C. Reed, On the effect of boron on grain boundary character in a new polycrystalline superalloy, Acta Materialia 103 (2016) 688-699.

[30] O.C. Hellman, J.A. Vandenbroucke, J. Rusing, D. Isheim, D.N. Seidman, Analysis of threedimensional atom-probe data by the proximity histogram, Microscopy and Microanalysis 6(5) (2000) 437-444.

[31] R.R. Dehoff, M.M. Kirka, W.J. Sames, H. Bilheux, A.S. Tremsin, L.E. Lowe, S.S. Babu, Site specific control of crystallographic grain orientation through electron beam additive manufacturing, Materials Science and Technology 31(8) (2015) 931-938.

[32] H. Helmer, A. Bauereiss, R.F. Singer, C. Korner, Grain structure evolution in Inconel 718 during selective electron beam melting, Materials Science and Engineering a-Structural Materials Properties Microstructure and Processing 668 (2016) 180-187.

[33] S. Tammas-Williams, H. Zhao, F. Leonard, F. Derguti, I. Todd, P.B. Prangnell, XCT analysis of the influence of melt strategies on defect population in Ti-6Al-4V components manufactured by Selective Electron Beam Melting, Materials Characterization 102 (2015) 47-61.

[34] M. Rappaz, A. Jacot, W.J. Boettinger, Last-stage solidification of alloys: Theoretical model of dendrite-arm and grain coalescence, Metallurgical and Materials Transactions A-Physical Metallurgy and Materials Science 34(3) (2003) 467-479.

[35] P. Rong, N. Wang, L. Wang, R.N. Yang, W.J. Yao, The influence of grain boundary angle on the hot cracking of single crystal superalloy DD6, Journal of Alloys and Compounds 676 (2016) 181-186. [36] L.M. Sochalski-Kolbus, E.A. Payzant, P.A. Cornwell, T.R. Watkins, S.S. Babu, R.R. Dehoff, M. Lorenz, O. Ovchinnikova, C. Duty, Comparison of Residual Stresses in Inconel 718 Simple Parts Made by Electron Beam Melting and Direct Laser Metal Sintering, Metallurgical and Materials Transactions A-Physical Metallurgy and Materials Science 46A(5) (2015) 2322-2322.

[37] R.C. Reed, THE SUPERALLOYS: Fundamentals and Applications, Cambridage University Press ed.2006.

[38] W.J. Sames, K.A. Unocic, G.W. Helmreich, M.M. Kirka, F. Medina, R.R. Dehoff, S.S. Babu, Feasibility of in situ controlled heat treatment (ISHT) of Inconel 718 during electron beam melting additive manufacturing, Additive Manufacturing 13 (2017) 156-165.

[39] O.A. Ojo, N.L. Richards, M.C. Chaturvedi, Study of the fusion zone and heat-affected zone microstructures in tungsten inert gas-welded INCONEL 738LC superalloy, Metallurgical and Materials Transactions a-Physical Metallurgy and Materials Science 37A(2) (2006) 421-433. [40] M.L. Zhong, H.Q. Sun, W.J. Liu, X.F. Zhu, J.J. He, Boundary liquation and interface cracking characterization in laser deposition of Inconel 738 on directionally solidified Ni-based superalloy, Scripta Materialia 53(2) (2005) 159-164.

[41] O.A. Ojo, N.L. Richards, M.C. Chaturvedi, Contribution of constitutional liquation of gamma prime precipitate to weld HAZ cracking of cast Inconel 738 superalloy, Scripta Materialia 50(5) (2004) 641-646.

[42] E. Cadel, D. Lemarchand, S. Chambreland, D. Blavette, Atom probe tomography investigation of the microstructure of superalloys N18, Acta Materialia 50(5) (2002) 957-966.

[43] P.A.J. Bagot, O.B.W. Silk, J.O. Douglas, S. Pedrazzini, D.J. Crudden, T.L. Martin, M.C. Hardy, M.P. Moody, R.C. Reed, An Atom Probe Tomography study of site preference and partitioning in a nickel-based superalloy, Acta Materialia 125 (2017) 156-165.

[44] L. Letellier, S. Chambreland, P. Duval, D. Blavette, Grain-Boundary Segregation in Nickel-Base Superalloys Astroloy - An Atom-Probe Study, Applied Surface Science 67(1-4) (1993) 305-310.

[45] L. Letellier, M. Guttmann, D. Blavette, Atomic-Scale Investigation of Grain-Boundary

Microchemistry in the Nickel-Based Superalloy Astroloy with a 3-Dimensional Atom-Probe, Philosophical Magazine Letters 70(4) (1994) 189-194.

[46] L. Letellier, A. Bostel, D. Blavette, Direct Observation of Boron Segregation at Grain-Boundaries in Astroloy by 3D Atomic Tomography, Scripta Metallurgica et Materialia 30(12) (1994) 1503-1508.

[47] D. Heydari, A.S. Fard, A. Bakhshi, J.M. Drezet, Hot tearing in polycrystalline Ni-based IN738LC superalloy: Influence of Zr content, Journal of Materials Processing Technology 214(3) (2014) 681687. 
[48] D. Raabe, M. Herbig, S. Sandlobes, Y. Li, D. Tytko, M. Kuzmina, D. Ponge, P.P. Choi, Grain boundary segregation engineering in metallic alloys: A pathway to the design of interfaces, Current Opinion in Solid State and Materials Science 18(4) (2014) 253-261.

[49] D. Tytko, P.P. Choi, J. Klower, A. Kostka, G. Inden, D. Raabe, Microstructural evolution of a Nibased superalloy (617B) at 700 degrees $\mathrm{C}$ studied by electron microscopy and atom probe tomography, Acta Materialia 60(4) (2012) 1731-1740.

[50] J.O. Andersson, T. Helander, L.H. Hoglund, P.F. Shi, B. Sundman, THERMO-CALC \& DICTRA, computational tools for materials science, Calphad-Computer Coupling of Phase Diagrams and Thermochemistry 26(2) (2002) 273-312.

[51] M. Rappaz, J.M. Drezet, M. Gremaud, A new hot-tearing criterion, Metallurgical and Materials Transactions A-Physical Metallurgy and Materials Science 30(2) (1999) 449-455.

[52] L. Wang, N. Wang, N. Provatas, Liquid channel segregation and morphology and their relation with hot cracking susceptibility during columnar growth in binary alloys, Acta Materialia 126 (2017) 302-312.

[53] Z. Feng, T. Zacharia, S.A. David, Thermal stress development in a nickel based superalloy during weldability test, Welding Journal 76(11) (1997) S470-S483.

[54] S.S. Babu, S.A. David, J.W. Park, J.M. Vitek, Joining of nickel base superalloy single crystals, Science and Technology of Welding and Joining 9(1) (2004) 1-12.

[55] P. Mercelis, J.P. Kruth, Residual stresses in selective laser sintering and selective laser melting, Rapid Prototyping Journal 12(5) (2006) 254-265. 

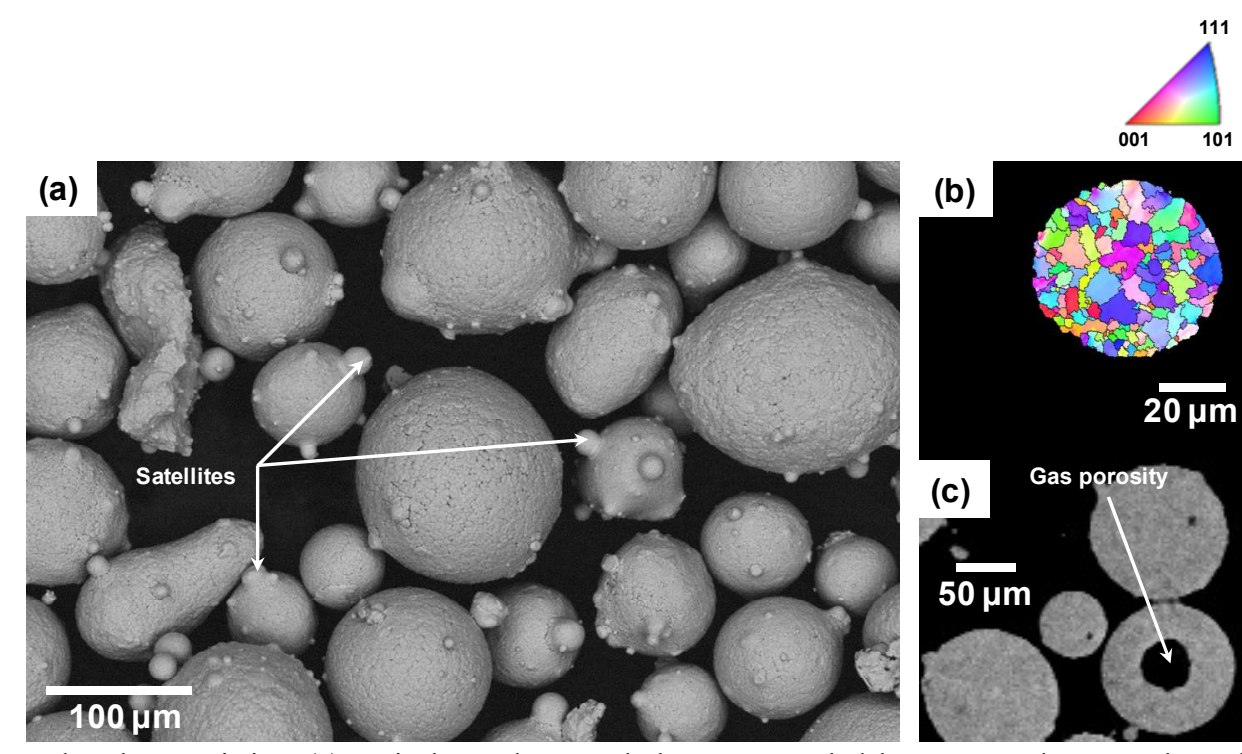

Figure 1. Powder characteristics: (a) typical powder morphology as-revealed by SEM under secondary electron contrast (SE); (b) IPF-EBSD map revealing that the powder particles are polycrystalline; (c) SE-SEM micrograph illustrating gas porosity within initial powder particles.
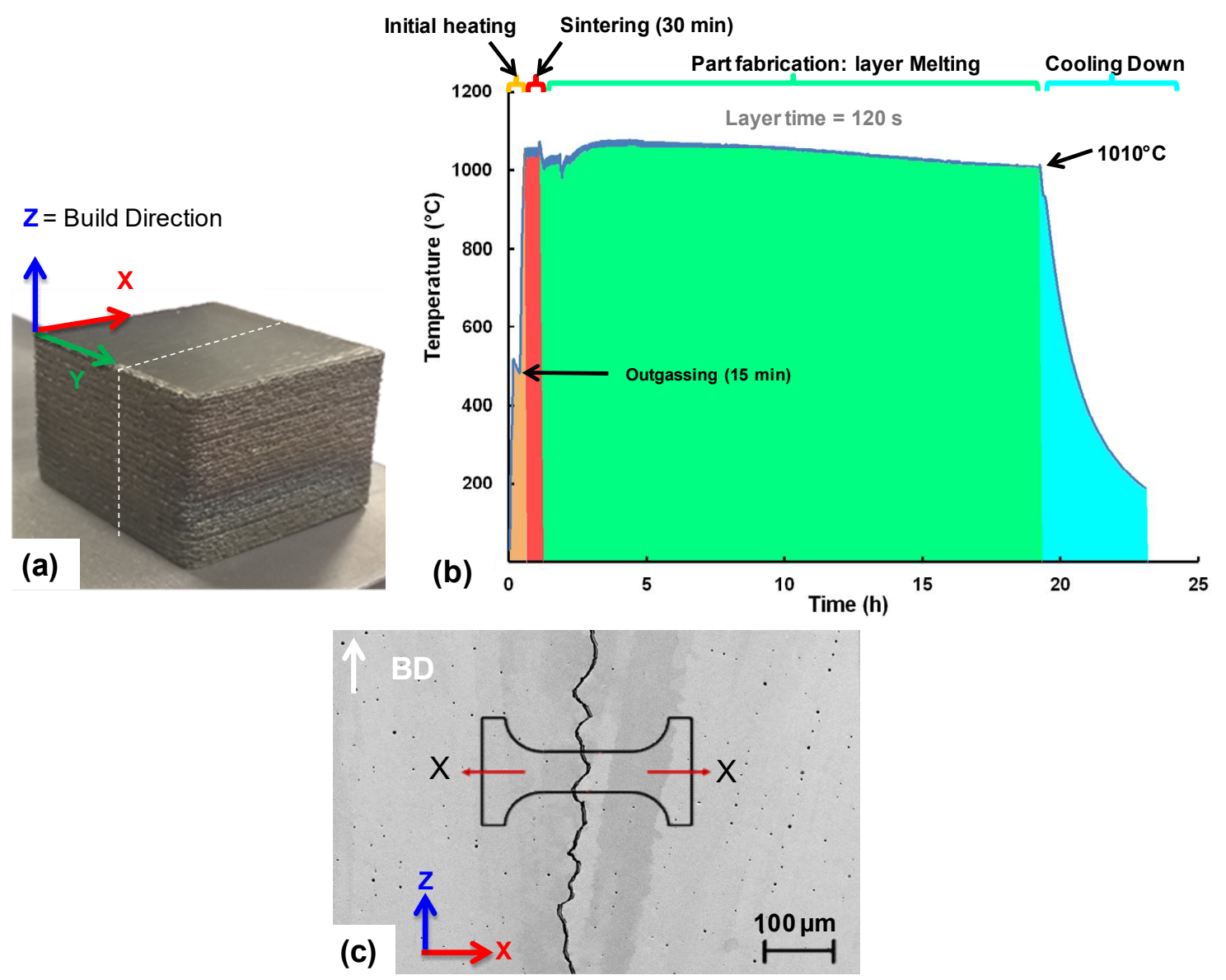

Figure 2. (a) Typical S-EBM as-built cubic sample, highlighted in white the plane of observations (XZ). (b) Temperature profile measured at the bottom of the substrate throughout the build and corresponding stages of fabrication. Layer time is also indicated. (c) Schematic showing the plane from which were extracted the micro-tensile specimens. 


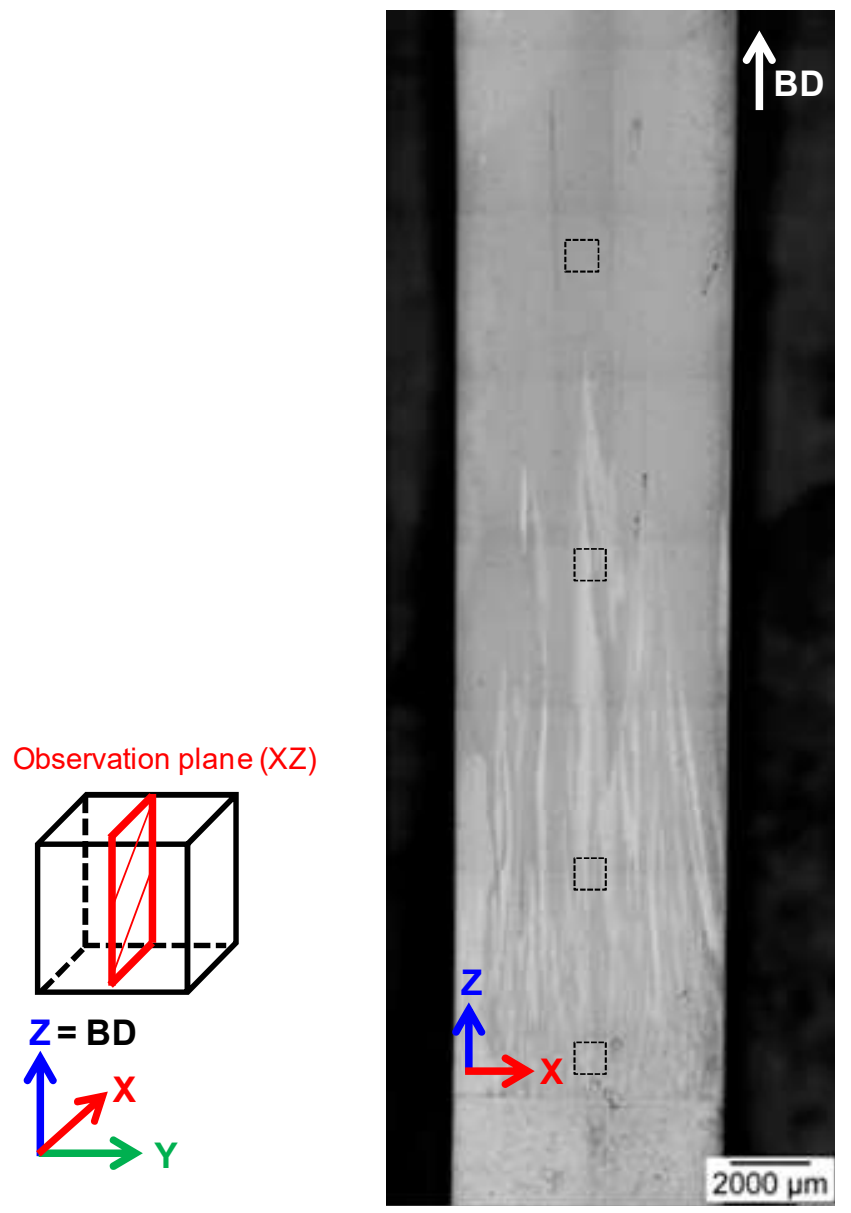

(a)
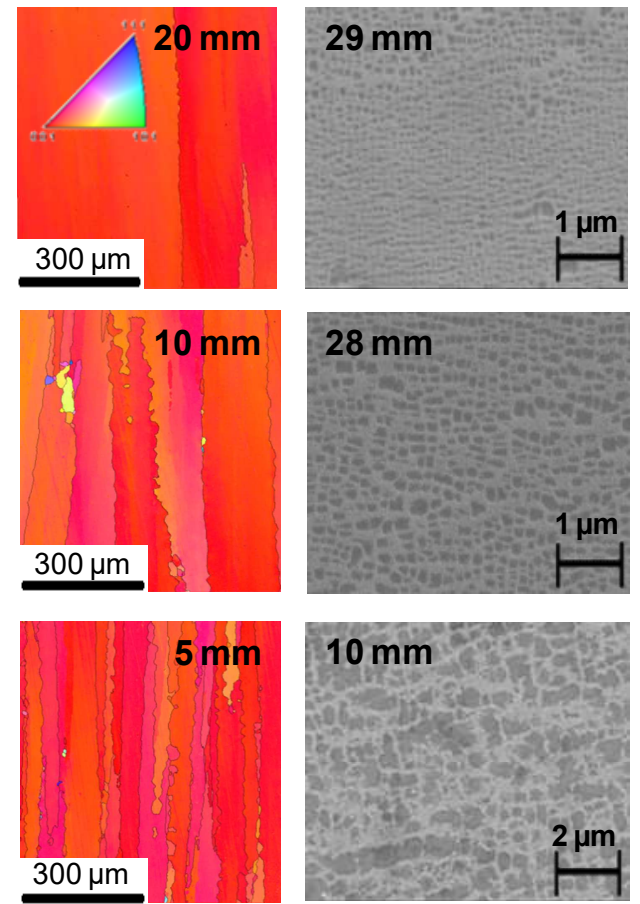

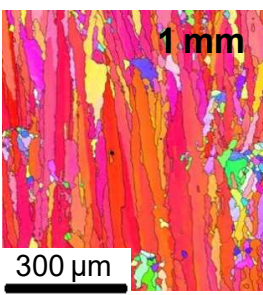

(b)

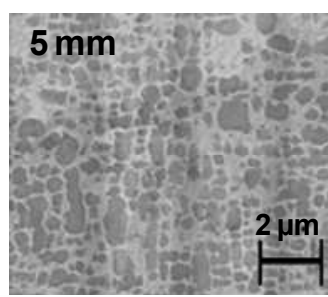

(c)

Figure 3. Typical microstructure of an as-built specimen observed in the central part on a XZ cross section. (a) Optical micrograph showing the macrostructure. (b) EBSD-IPF maps showing the columnar grain size evolution and (c) BSE-SEM micrographs illustrating the size of the $\gamma^{\prime}$ precipitates at different positions along the build direction. Black dashed square boxes indicate the position where the EBSD maps were acquired. Note that EBSD maps and BSE-SEM images are not necessarily shown at the same location as the evolution of grain and precipitate size do not occur at similar position along the build direction. 

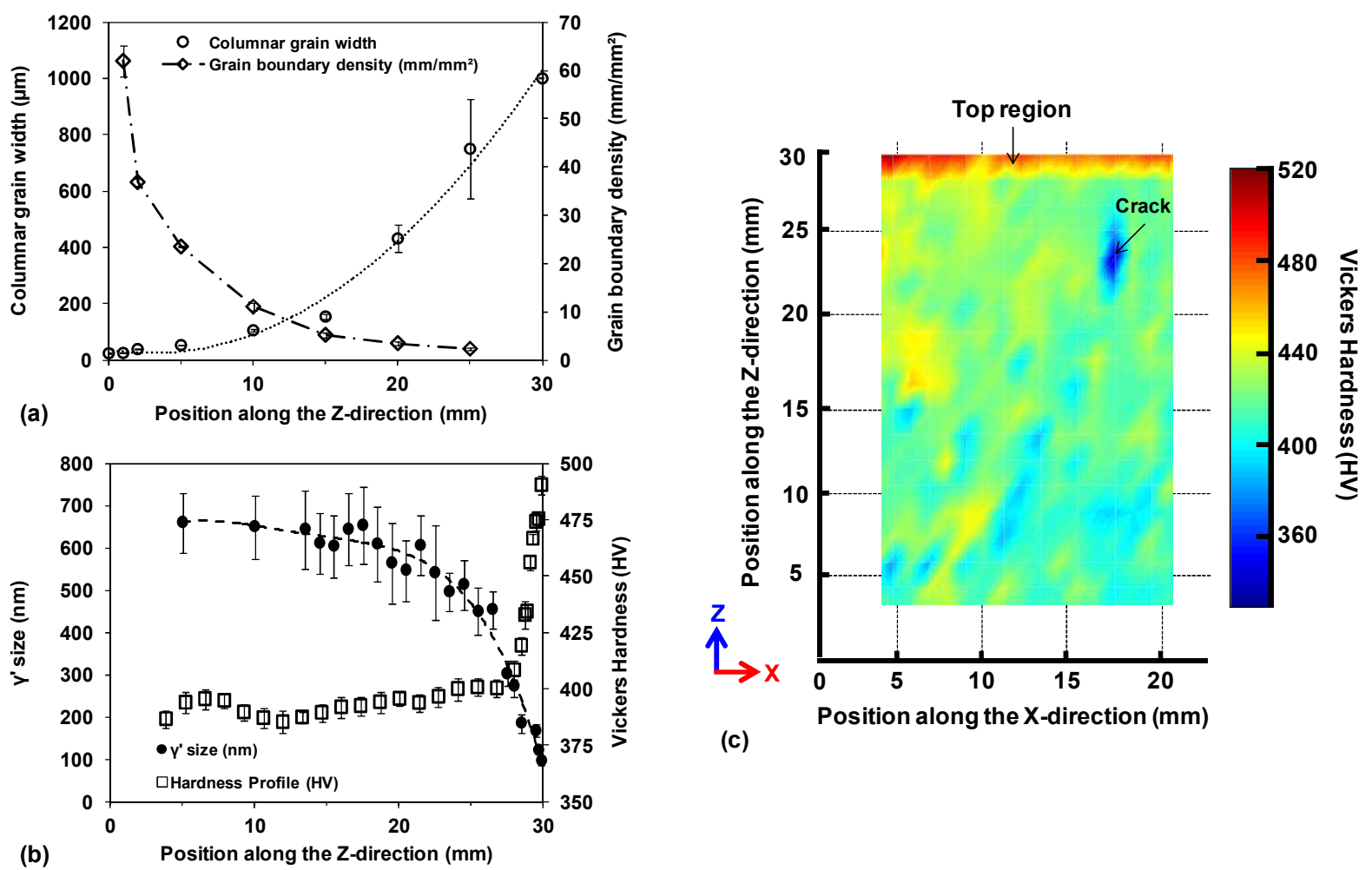

(c)

Figure 4. (a) Evolution of the columnar grain width and grain boundary density along the build direction (Z-direction). (b) Evolution of the hardness and $\gamma^{\prime}$ size along the build direction (Z-direction). (c) Hardness map over a XZ cross section extracted from the central region of a cube sample. 

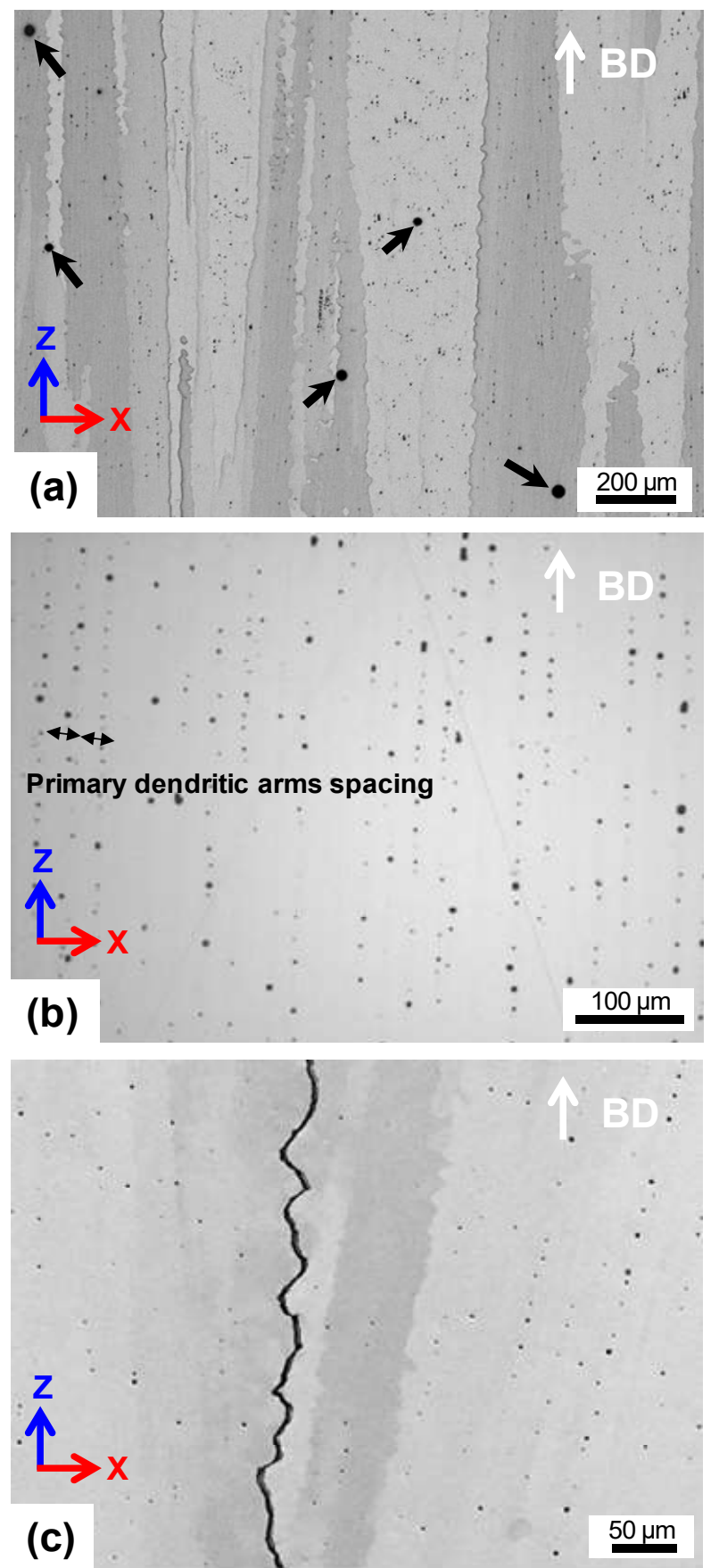

Figure 5. Micrographs showing the different defects observed in the as-built specimens. (a) Optical micrograph showing randomly distributed perfectly spherical pores corresponding to gas porosity and pointed out by black arrows. (b) SE-SEM micrograph showing intragranular well-aligned rounded-shape pores (microshrinkage) corresponding to intragranular dendrites coalescence. (c) BSE-SEM micrograph illustrating a crack running along the build direction (BD). 

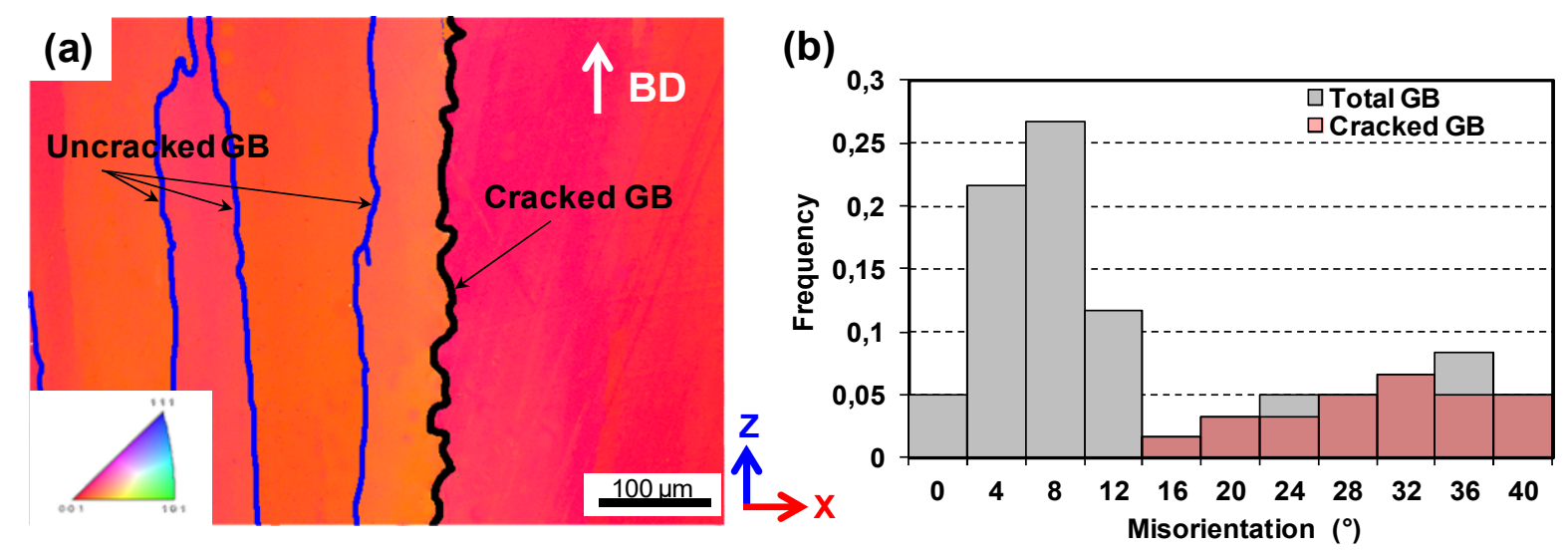

Figure 6. (a) IPF-EBSD map illustrating that cracks propagate along HAGB ( $>15^{\circ}$ in black), LAGB are highlighted in blue $\left(5<\right.$ LAGB $\left.<15^{\circ}\right)$. The cracks was found to propagate along the HAGB displayed in black. (b) Histogram displaying the distribution of the grain boundaries (gray), in red the distribution of the cracked grain boundaries.
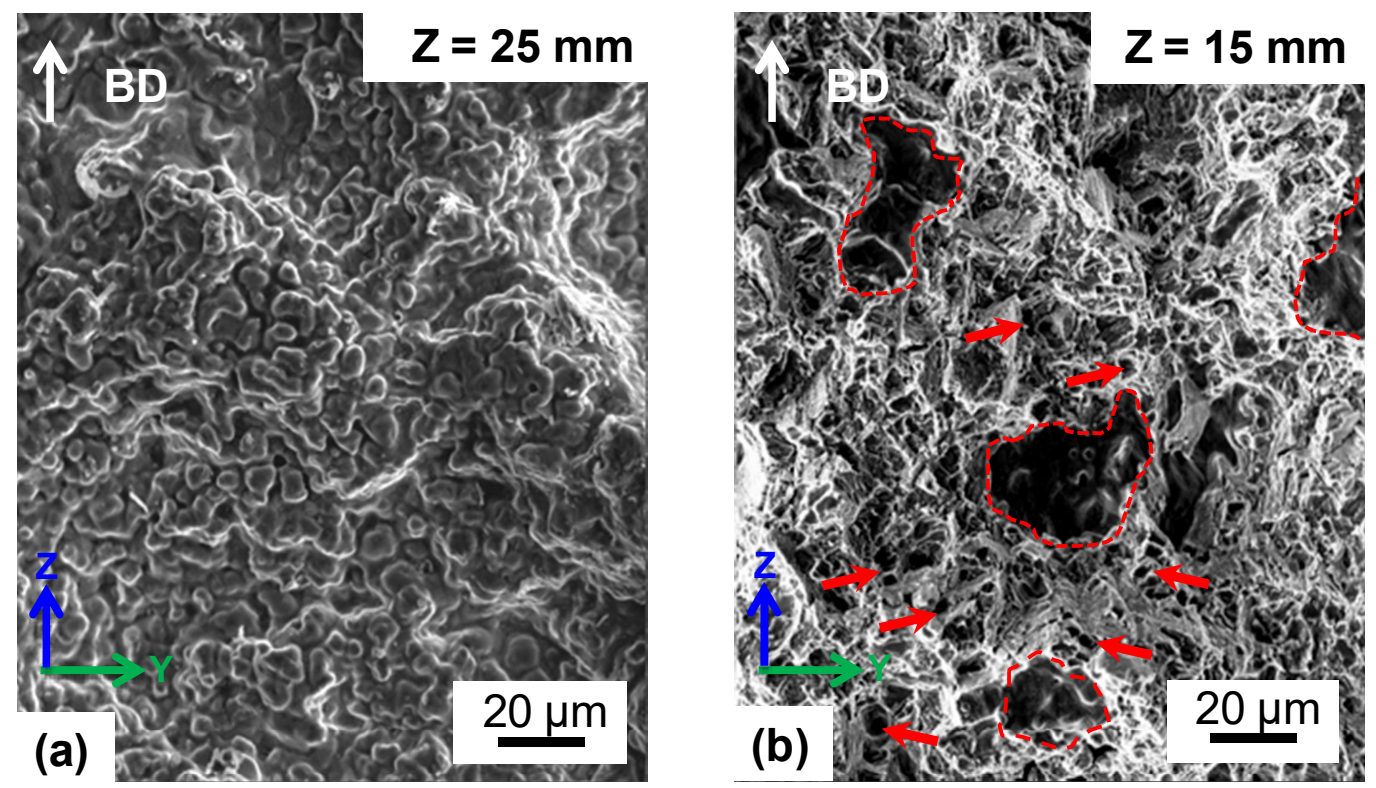

Figure 7. (a) Fracture surface of a HAGB exhibiting a dendritic morphology suggesting the presence of a continuous liquid film $(Z=25 \mathrm{~mm})$. (b) Fracture surface showing features typical of a ductile fracture (some dimples are pointed out by red arrows) and features that are most likely the liquid drops (marked in red) entrapped during the coalescence of secondary dendrite arms $(Z=15 \mathrm{~mm})$. 

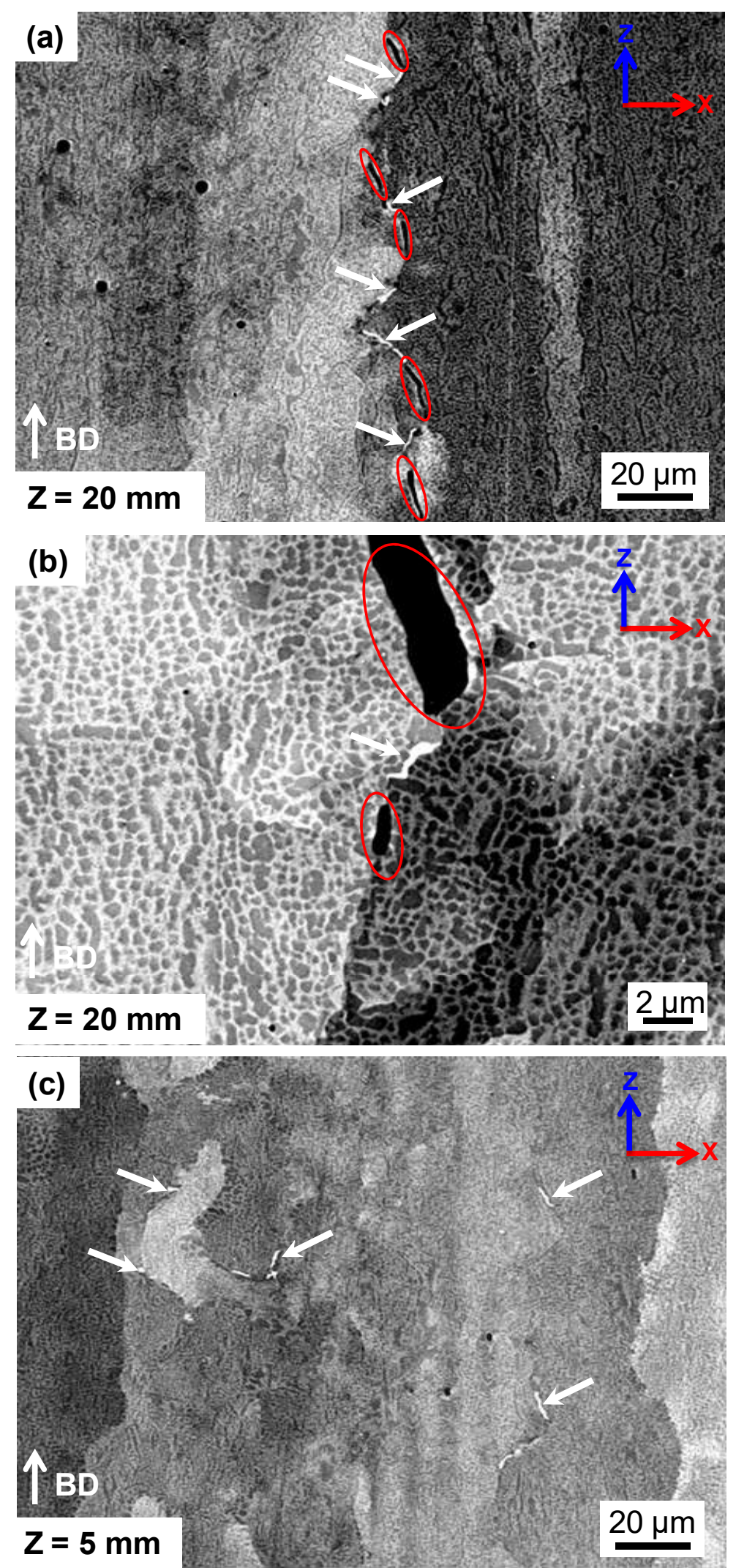

Figure 8. (a) Low magnification BSE- SEM micrograph and (b) high magnification BSE-SEM micrograph taken at $Z=20$ $\mathrm{mm}$ (cracked region) showing the tip of a cracked HAGB. Note that only one HAGB can be observed and that it is decorated by second phase particles pointed out by white arrows. Damage is highlighted in red. (c) BSE- SEM micrograph taken at $Z=$ $5 \mathrm{~mm}$ (uncracked region). Several HAGB can be observed but not all of them are decorated by second phase particles marked by black arrows. 

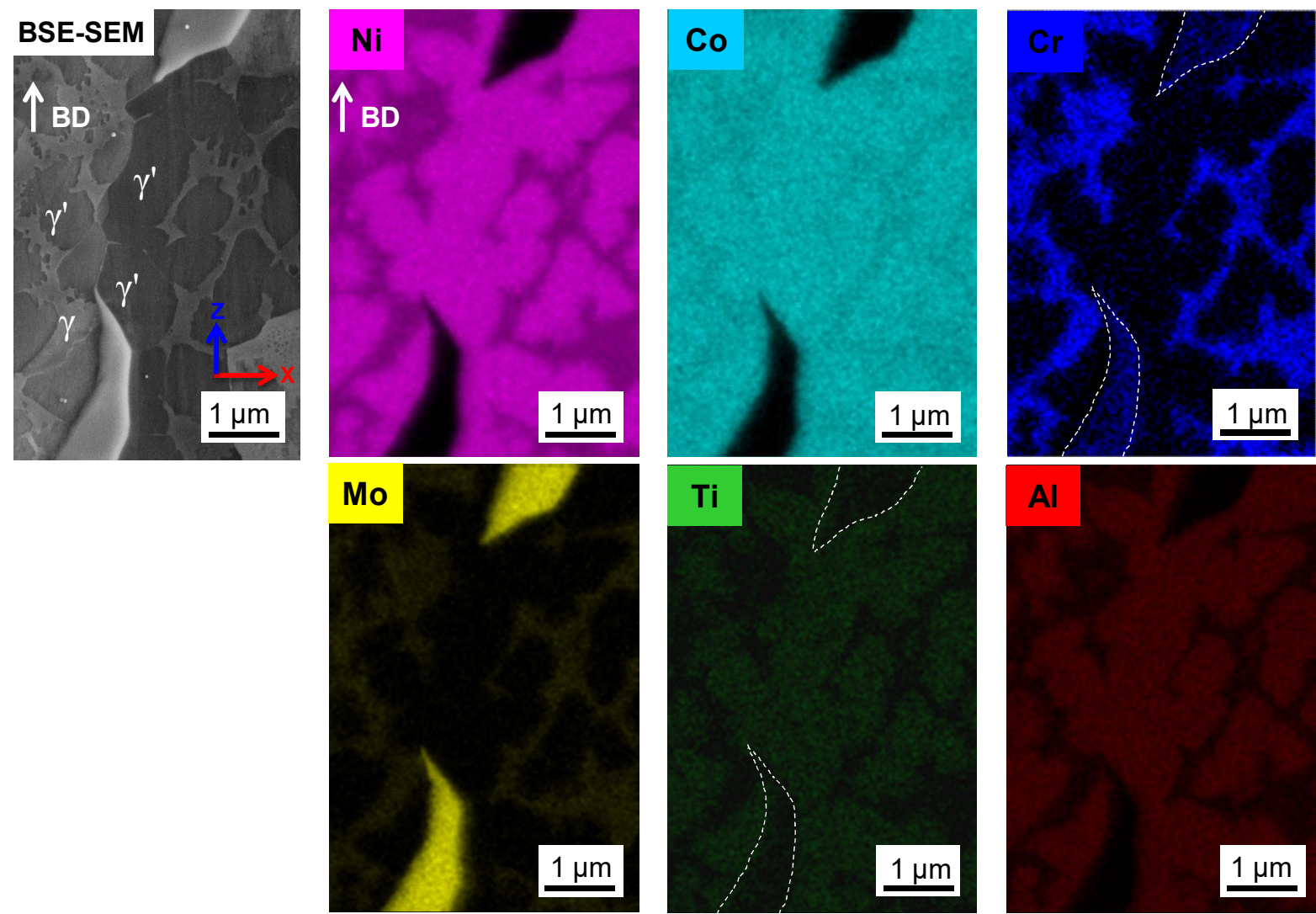

Figure 9. BSE-SEM image and associated EDX maps of the main alloying elements of a region of interest located at the tip of a cracked HAGB $(Z=20 \mathrm{~mm})$. Second phase particle containing $\mathrm{Cr}$ and Mo-enriched. Second phase particles are highlighted by white dashed lines on maps where it is not easy to distinguish them. 


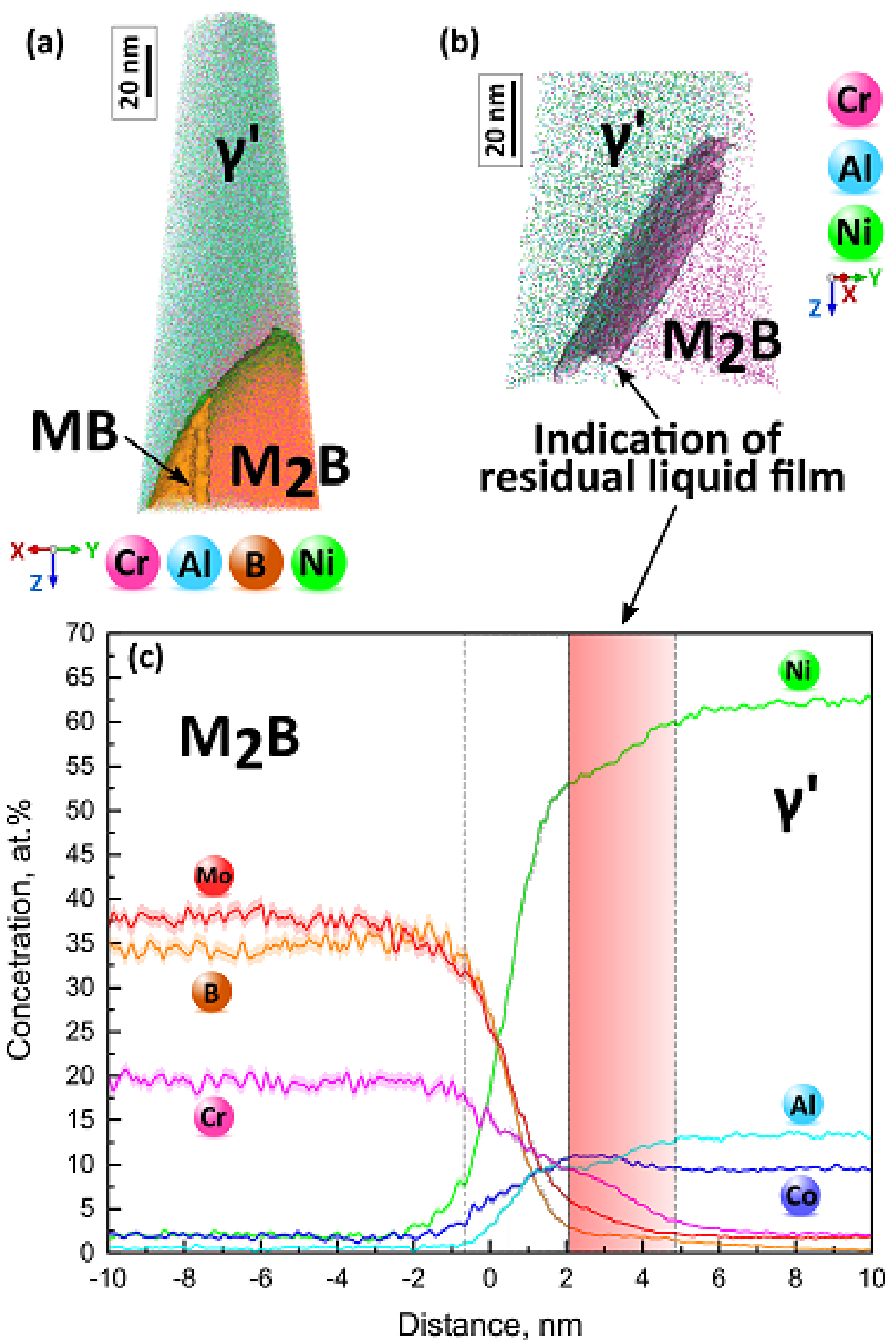

Figure 10. (a) A $3 \mathrm{D}$ atom probe reconstruction containing $M B$ and $\mathrm{M}_{2} \mathrm{~B}$ type borides alongside with an intergranular $\gamma^{\prime}$ particle with iso-concentration interfaces shown at 34 at.\% $\mathrm{Ni}$ (green) and 46 at.\% B (orange). (b) Zoom on the region at the interface showing the region depicted in red in (c) with an iso-density surface with $4 \mathrm{Cr}$ atoms per $\mathrm{nm}^{3}$. (c) Concentration profile analysis at $\gamma^{\prime} / \mathrm{M}_{2} \mathrm{~B}$ interface showing concentration of $\mathrm{Ni}, \mathrm{Al}, \mathrm{Co}, \mathrm{Mo}, \mathrm{B}$ and $\mathrm{Cr}$. Highlighted in red is the region suspected to be a "tracer" of the residual liquid film. Error bars are shown as lines filled with colour. 


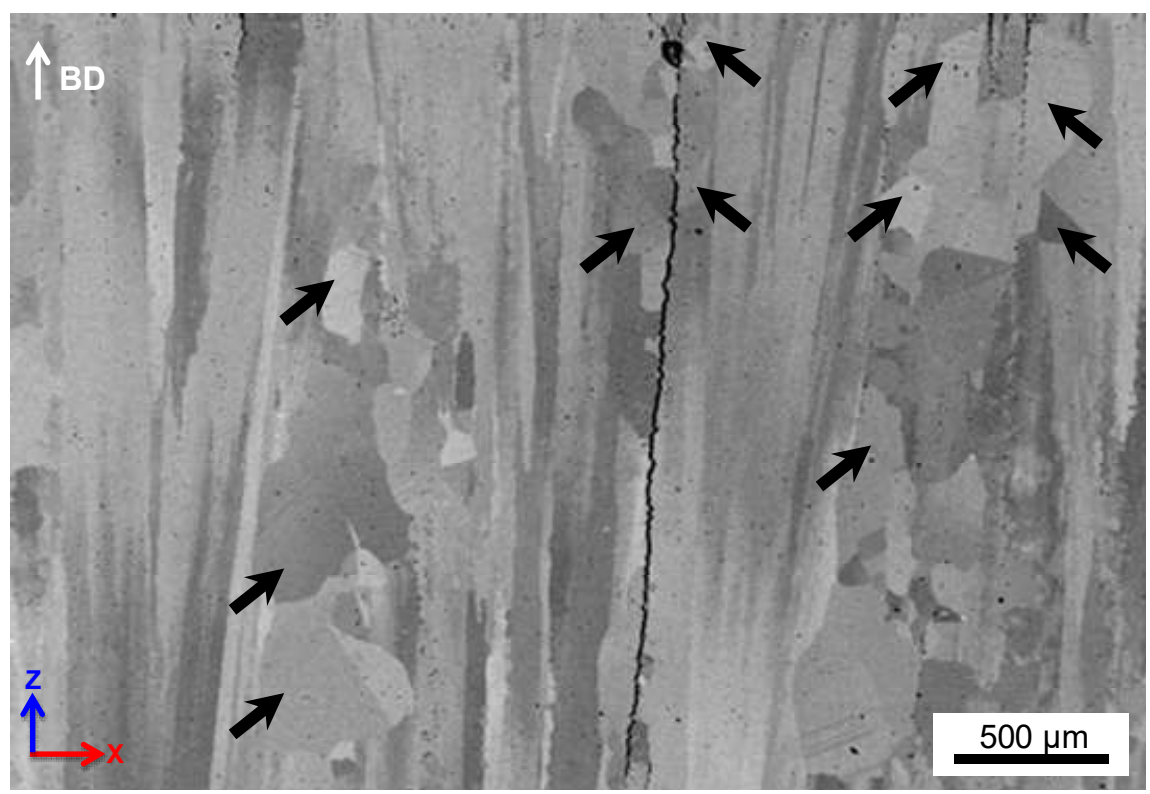

Figure 11. Typical BSE-SEM micrographs after a solutionizing heat treatment: $1190^{\circ} \mathrm{C} / 4 \mathrm{~h}$ followed by air quenching depicting regions where recrystallization occurred (Recrystallized grains are pointed out by black arrows).

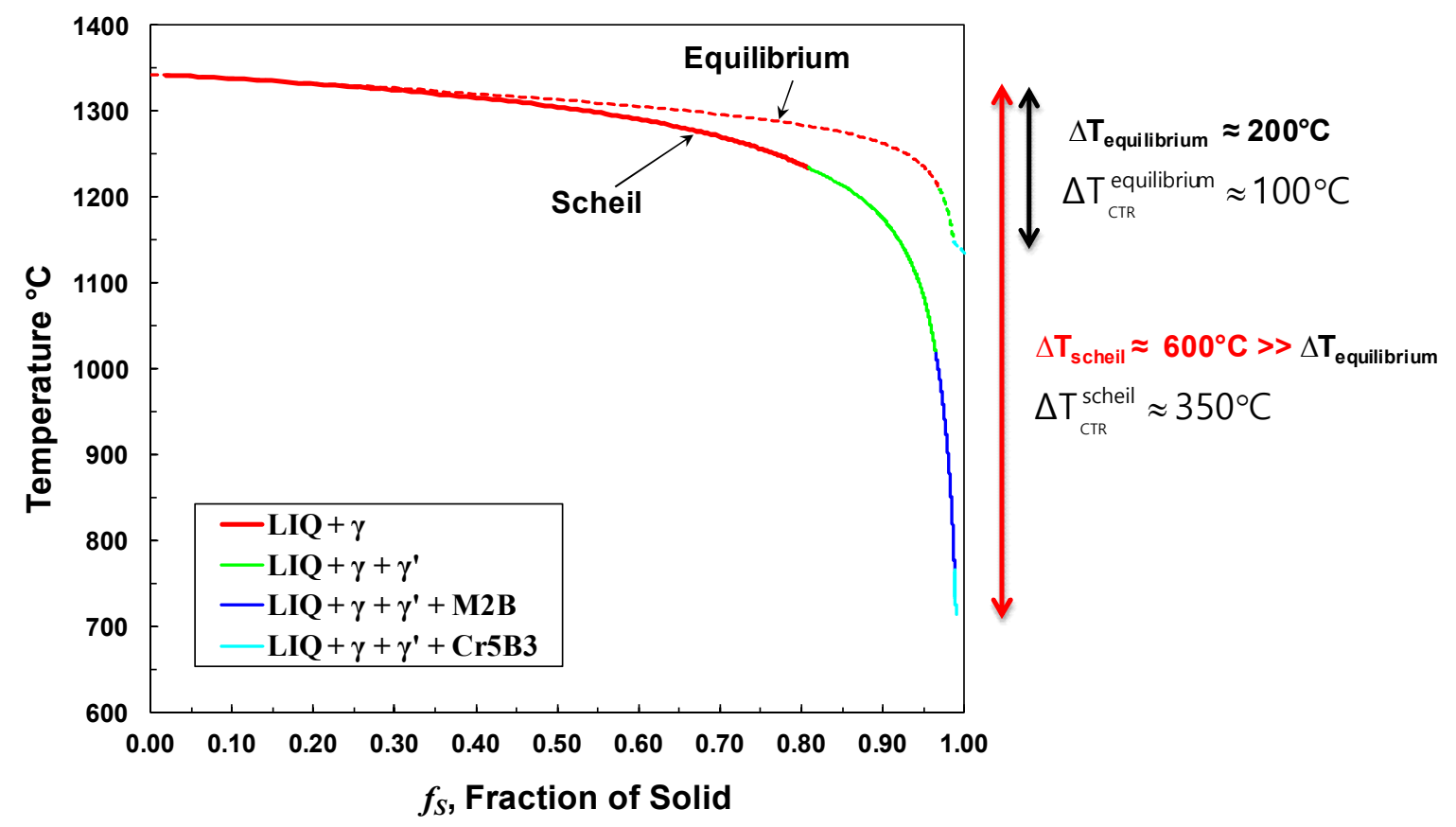

Figure 12. (a) Thermodynamic calculations of the solidification path of the investigated material based respectively on equilibrium and Scheil-Gulliver assumption. Solidification ranges denoted $\Delta \mathrm{T}$ and critical temperature ranges denoted $\Delta \mathrm{T}_{\mathrm{CTR}}$. are specified for both equilibrium and non-equilibrium assumptions. 


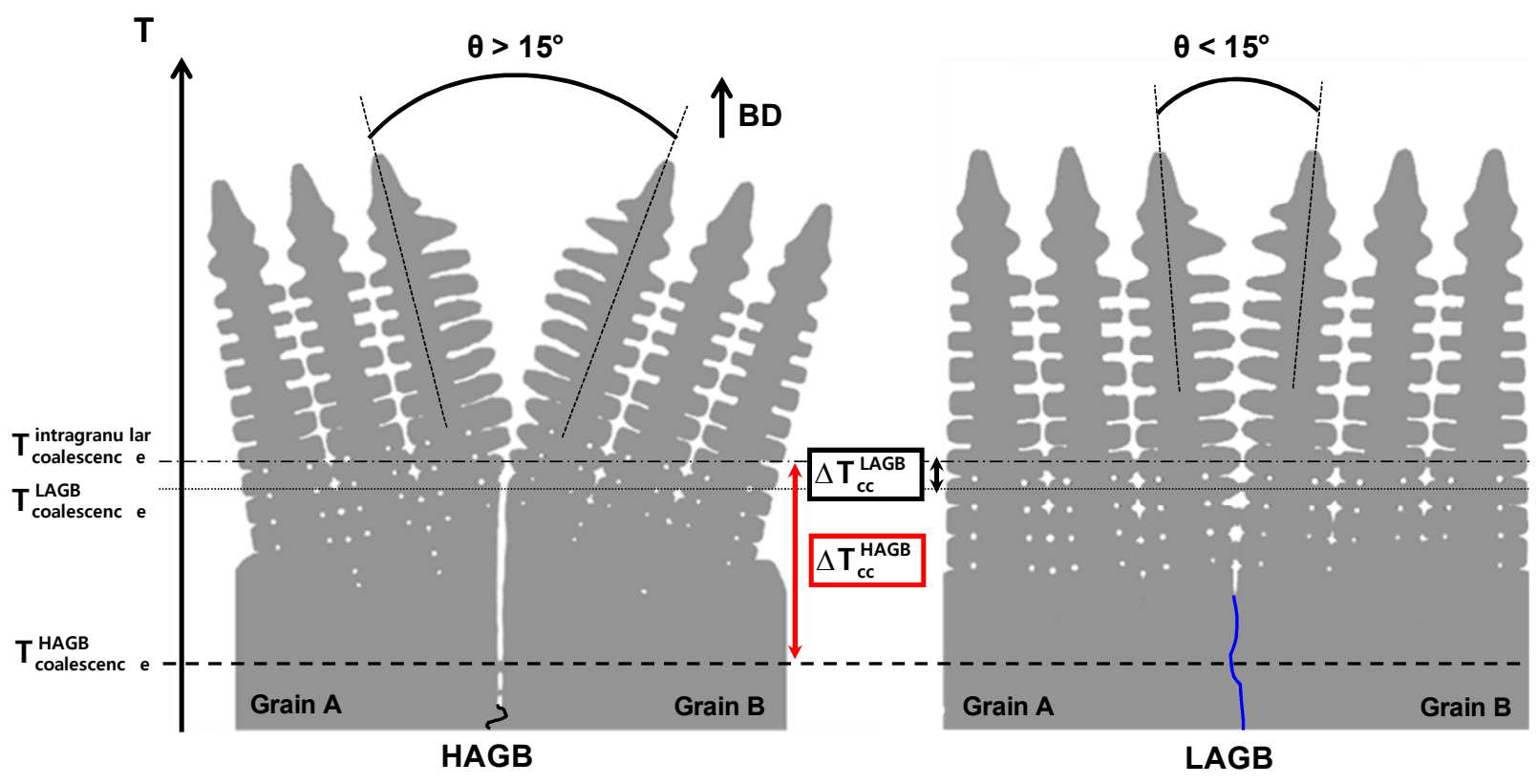

(a)

(b)

Figure 13. Schematic illustration of the last stage of solidification during columnar dendritic solidification : (a) for a "repulsive" high angle grain boundary (HAGB) and (b) for an "attractive" low angle grain boundary (LAGB). Liquid in white, solid in gray. 